\title{
Methylamines as Nitrogen Precursors in Chemical Vapor Deposition of Gallium Nitride
}

Karl Rönnby, Sydney C. Buttera, Polla Rouf, Sean T. Barry, Lars Ojamäe and Henrik Pedersen

The self-archived postprint version of this journal article is available at Linköping University Institutional Repository (DiVA):

http://urn.kb.se/resolve?urn=urn:nbn:se:liu:diva-156198

N.B.: When citing this work, cite the original publication.

Rönnby, K., Buttera, S. C., Rouf, P., Barry, S. T., Ojamäe, L., Pedersen, H., (2019), Methylamines as Nitrogen Precursors in Chemical Vapor Deposition of Gallium Nitride, The Journal of Physical

Chemistry C, 123(11), 6701-6710. https://doi.org/10.1021/acs.jpcc.9bo0482

Original publication available at:

https://doi.org/10.1021/acs.jpcc.9bo0482

Copyright: American Chemical Society

http://pubs.acs.org/ 


\title{
Methylamines as Nitrogen Precursors in Chemical Vapor Deposition of Gallium Nitride
}

Karl Rönnby ${ }^{1 *}$, Sydney C. Buttera ${ }^{2}$, Polla Rouf ${ }^{1}$, Seán T. Barry ${ }^{2}$, Lars Ojamäe ${ }^{1}$, Henrik Pedersen $^{1}$

${ }^{1}$ Department of Physics, Chemistry and Biology, Linköping University, SE-581 83 Linköping, Sweden

${ }^{2}$ Department of Chemistry, Carleton University, 1125 Colonel By Drive, Ottawa, ON, Canada, K1S5B6

*Corresponding author: henrik.pedersen@liu.se; Twitter: @hacp81

\begin{abstract}
Chemical vapor deposition (CVD) is one of the most important techniques for depositing thin films of the group 13 nitrides (13-Ns), AlN, GaN, InN and their alloys, for electronic device applications. The standard CVD chemistry for 13-Ns use ammonia as the nitrogen precursor, however, this gives an inefficient CVD chemistry forcing N/13 ratios of 100/1 or more. Here we investigate the hypothesis that replacing the N-H bonds in ammonia with weaker N-C bonds in methylamines will permit better CVD chemistry, allowing lower CVD temperatures and an improved N/13 ratio. Quantum chemical computations shows that while the methylamines have a more reactive gas phase chemistry, ammonia has a more reactive surface chemistry. CVD experiments using methylamines failed to deposit a continuous film, while instead micrometer sized gallium droplets were deposited. This study shows that the nitrogen surface chemistry is most likely more important to consider than the gas phase chemistry when searching for better nitrogen precursors for 13-N CVD.
\end{abstract}




\section{Introduction}

The group 13 nitrides (13-Ns or III-Ns), AlN, GaN, InN and their alloys, form an increasingly important class of semiconductor materials with applications in light emitting diodes (LEDs), laser diodes, high electron mobility transistors (HEMTs), radio frequency (RF) devices, and power transistors. Regardless of the application, one of the most popular methods used to deposit thin layers of 13-Ns is chemical vapor deposition (CVD), where typically trimethyl metal complexes $\left(\mathrm{M}\left(\mathrm{CH}_{3}\right)_{3}\right.$, where $\mathrm{M}=\mathrm{Al}, \mathrm{Ga}$ or $\left.\mathrm{In}\right)$ and ammonia $\left(\mathrm{NH}_{3}\right)$ are used as group 13 and nitrogen precursors, respectively. ${ }^{1}$ The reaction pathways of the trimethyl gallium $\left(\mathrm{Ga}\left(\mathrm{CH}_{3}\right)_{3}\right) / \mathrm{NH}_{3}$ system has been studied earlier, both experimentally and theoretically. ${ }^{2,3,4,5,6,7}$ The studies show a complex gas phase chemistry where both $\mathrm{Ga}\left(\mathrm{CH}_{3}\right)_{3}$ and $\mathrm{NH}_{3}$ could decompose to more reactive species that could deposit on the surface or react in the gas phase to form species containing both gallium and nitrogen. $\mathrm{Ga}\left(\mathrm{CH}_{3}\right)_{3}$ is a Lewis acid due to the empty p-orbital on the metal center and ammonia exists with a free electron pair on the nitrogen, making it a Lewis base; for this reason, Lewis adduct formation of $\mathrm{H}_{3} \mathrm{~N}: \mathrm{Ga}\left(\mathrm{CH}_{3}\right)_{3}$ is very likely, especially with the Le Chatelier's driving force provided by the large surplus of ammonia in the CVD gas mixture. It has been suggested that such adducts either break up at the high temperatures employed in CVD of 13-Ns or undergo a reaction where a M-N bond is formed with release of methane. ${ }^{8,9,10}$ The formation of $\mathrm{H}_{2} \mathrm{~N}-\mathrm{M}\left(\mathrm{CH}_{3}\right)_{2}$ could contribute to the growth of GaN by deposition, but might be also detrimental to the CVD process by leading to the formation of parasitic nitride nanoparticles in the gas phase. $3,9,11,12,13$

Despite the fact that CVD processes for 13-Ns have reached a level of maturity that allows them to be used for industrial production of $13-\mathrm{N}$ based electronics, they typically require a very high $\mathrm{NH}_{3} / 13$ precursor ratio, typically $100-1000: 1$ for $\mathrm{AlN}$ and $\mathrm{GaN}^{1}$, and up to $10^{5}: 1$ for $\mathrm{InN}^{14}$, reflecting poorly tuned CVD chemistry. From a purely thermodynamic point of view, $\mathrm{NH}_{3}$ will mainly decompose under deposition conditions to highly stable dinitrogen and dihydrogen via the reactive species $\mathrm{NH}_{2}$ and $\mathrm{NH} .{ }^{15}$ However, kinetically, $\mathrm{NH}_{2}$ and $\mathrm{NH}$ intermediates only react to form dinitrogen and dihydrogen over longer timescales that are not typically accessible under normal CVD conditions. ${ }^{16}$ It has previously been demonstrated that $\mathrm{NH}_{3}$ has a very low reactivity at typical CVD temperatures for $\mathrm{AlN}$ and GaN depositions, and its decomposition by catalysis by iron from the CVD reactor's components has shown to improve ammonia reactivity. ${ }^{17}$ The need to use high $\mathrm{NH}_{3} / 13$ precursor ratios in CVD of group 13 nitrides points to poorly matched precursor kinetics making it interesting to study alternative nitrogen precursors. 
This study investigates whether replacing one or more of the N-H bonds (bond dissociation energy: $450 \mathrm{~kJ} / \mathrm{mol}^{18}$ ) in $\mathrm{NH}_{3}$ with $\mathrm{N}-\mathrm{C}$ bonds (bond dissociation energy $356 \mathrm{~kJ} / \mathrm{mol}^{19}$ ) will lead to a more efficient nitrogen precursor; this change would produce a precursor with weaker bonds and lower symmetry as a result of substituting one or two hydrogens with methyl groups, hopefully increasing its reactivity to deposit group 13 nitride films. Quantum chemical calculations were used to study the possible gas phase chemical reactions in the decomposition of $\mathrm{NH}_{3-\mathrm{x}}\left(\mathrm{CH}_{3}\right)_{\mathrm{x}}$ with $\mathrm{x}=0-3$. The subsequent surface chemical interactions with the reactive fragments with a GaN surface were also studied using quantum chemical calculations. Since the Lewis adduct formation between acidic group 13 precursors and basic $\mathrm{N}$ precursors is an important aspect of the gas phase chemistry for CVD of 13-Ns, it has also been studied by quantum chemical computations in this work. The quantum chemical study is further compared to an experimental CVD study where $\mathrm{NH}_{2} \mathrm{CH}_{3}, \mathrm{NH}\left(\mathrm{CH}_{3}\right)_{2}$ and $\mathrm{N}\left(\mathrm{CH}_{3}\right)_{3}$ were compared to $\mathrm{NH}_{3}$ as nitrogen precursors in a CVD process with $\mathrm{Ga}\left(\mathrm{CH}_{3}\right)_{3}$.

\section{Methods}

\section{Computational details}

Quantum chemical calculations were carried out with the Gaussian09 software suite ${ }^{20}$. The high accuracy Gaussian $4(\mathrm{G} 4)^{21}$ composite method was used for calculations on the gas phase molecular species, which enabled the derivation of thermochemical data for decomposition and adducts reactions. While the G4 method is well established for lighter elements ${ }^{22}$ there is less experience with its performance for e.g. gallium. Additional calculations using the coupled cluster approach were therefore performed for comparison. The G4 method somewhat overestimates the $\mathrm{Ga}_{-} \mathrm{CH}_{3}$ bond energy (around $10 \mathrm{~kJ} / \mathrm{mol}$ ) compared to those calculated at $\operatorname{CCSD}(\mathrm{T}) /$ aug-cc-pVTZ ${ }^{23}$ level of theory. The calculated adduct formation energies using G4 level of theory, $74.51 \mathrm{~kJ} / \mathrm{mol}$ for the enthalpy of forming the adduct between $\mathrm{NH}_{3}$ and $\mathrm{Ga}\left(\mathrm{CH}_{3}\right)_{3}$, are in good agreement with experimental values, -68.20 to $-77.82 \mathrm{~kJ} / \mathrm{mol}$ for the same reaction. ${ }^{24,25}$ The hybrid density functional theory (DFT) B3LYP method with the D3 version of Grimme's empirical dispersion ${ }^{26}$ and the 6-31G(2df,p) was used as the basis set for the surface interaction studies. For the surface studies, a hydrogen terminated model (0001) surface in the form of $\mathrm{a}(\mathrm{GaN}){ }_{13} \mathrm{H}_{32}$ cluster was used (See Fig. $\mathrm{S} 1$ in the supporting information). The effect of the size of the cluster on adsorption energies was investigated and are summarized in the supporting information. It was found that the effect was small, i.e. enlarging the cluster changed the adsorption energy by less than $1.84 \mathrm{~kJ} / \mathrm{mol}$. 
The geometries, for both equilibrium and transition state structures were optimized using the Berny algorithm as implemented in the Gaussian program with standard convergence criteria. The equilibrium structures were confirmed to have zero imaginary vibrational modes by vibrational normal-mode calculations while the transition state structures were confirmed to have one imaginary mode connecting the reactant and product structures. Gibbs free energies were obtained by adding zero-point energies and temperature-dependent energy contributions to the electronic energies along with entropic terms as computed from the vibrational normalmode frequencies and the optimized geometries. ${ }^{27}$ An investigation of the error in energies associated with treating the internal rotations as vibrations was performed, see supporting information for details. Due to the small differences in energies (less than $2 \mathrm{~kJ} / \mathrm{mol}$ for enthalpies and $3.2 \mathrm{~kJ} / \mathrm{mol}$ for free energies) obtained using the two methods the errors from this approximation were deemed not to significantly affect our conclusions and we chose to not include corrections for the internal rotations in our presented calculations.

\section{Experimental details}

The depositions of GaN films were undertaken in a horizontal hot-wall CVD system ${ }^{28}$ operating at 50 mbar with a carrier gas mixture of palladium membrane purified hydrogen $\left(\mathrm{H}_{2}\right)$ and nitrogen $\left(\mathrm{N}_{2}\right)(99.999 \%)$, at a volumetric $\mathrm{H}_{2} / \mathrm{N}_{2}$ ratio of 6.33 . Films were deposited on nominally on-axis $4 \mathrm{H}-\mathrm{SiC}(0001)$ substrates, cut into $2 \times 2 \mathrm{~cm}^{2}$ pieces, washed using standard RCA cleaning solutions ${ }^{29}$ : they were submerged in $\mathrm{NH}_{3}: \mathrm{H}_{2} \mathrm{O}_{2}: \mathrm{H}_{2} \mathrm{O}$ 1:1:5, rinsed in deionized water, submerged in $\mathrm{HCl}: \mathrm{H}_{2} \mathrm{O}_{2}: \mathrm{H}_{2} \mathrm{O}$ 1:1:6, rinsed again in deionized water, and finally dried with dry $\mathrm{N}_{2}$. Before each CVD experiment, an epitaxial aluminum nitride (AlN) nucleation layer was grown on the $\mathrm{SiC}$ substrate using $\mathrm{Al}\left(\mathrm{CH}_{3}\right)_{3}$ (SAFC Hightec EpiPure grade) and $\mathrm{NH}_{3}$ (99.9999\%, further purified using a Nanochem purifier down to $<1 \mathrm{ppb}$ for important contaminants such as water and oxygen) with a flow ratio of $\mathrm{NH}_{3} / \mathrm{Al}\left(\mathrm{CH}_{3}\right)_{3}=1043$ at $1200{ }^{\circ} \mathrm{C}$. The temperature was then lowered to $800-1000^{\circ} \mathrm{C}$ for the growth of GaN directly on the AIN layer using $\mathrm{Ga}\left(\mathrm{CH}_{3}\right)_{3}$ (SAFC Hightec EpiPure grade) and $\mathrm{NH}_{3}, \mathrm{NH}_{2} \mathrm{CH}_{3}$ (AGA, $99 \%$ ), $\mathrm{NH}\left(\mathrm{CH}_{3}\right)_{2}(\mathrm{AGA}, 99 \%)$ or $\mathrm{N}\left(\mathrm{CH}_{3}\right)_{3}(\mathrm{AGA}, 99 \%)$. All methylamines where further purified by a Micro Torr gas filter to reduce water and oxygen to less than $1 \mathrm{ppb}$.

We note, and would like to point out, that the methylamines, as compared to ammonia, are more challenging to work with in CVD experiments. The lower vapor pressure of the methylamines led, at one point, to condensation of amine in the gas lines and we therefore recommend that the gas lines and mass flow controllers are heated when attempting to replace ammonia with methylamines in a CVD setup. 
The morphology of the grown films was characterized using an optical microscope with Nomarski differential interference contrast and by a LEO 1550 Gemini scanning electron microscope (SEM) equipped with a field emission gun using 3-20 kV acceleration. Energydispersive X-ray spectroscopy (EDS) was used in the SEM for elemental analysis. An interference method ${ }^{30}$ was used to determine the thickness of the epitaxial layers. XRD

measurements were performed by employing PANalytical EMPYREAN MRD X-Ray diffractometer equipped with a $\mathrm{Cu}$-anode $\mathrm{x}$-ray tube and 5-axis (x-y-z-v-u) sample stage. For the determination of the crystalline structure of the thin films, glancing incidence XRD (GIXRD) was conducted. For these measurements, capillary optics on the incident beam side and parallel plate collimator on the detector side were used. The $\mathrm{Cu} K \beta$ line was removed by a Ni filter.

\section{Results}

\section{Gas phase decomposition of $\mathrm{NH}_{3-x}\left(\mathrm{CH}_{3}\right)_{x}$}

The optimized geometries of the NH3-x $\left(\mathrm{CH}_{3}\right) \mathrm{x}$ species and their decomposition products are given in Fig. 1. The studied gas phase decomposition reactions are summarized in Scheme 1.In these reaction paths the nitrogen atom consecutively loses a ligand (hydrogen atom or methyl group) and forms more reactive nitrogen radical species. The reactions are labeled " $\mathrm{H}$ " and " $\mathrm{C}$ " and correspond to the release of a hydrogen (vertical transitions) or a methyl radical (diagonal transitions), respectively. The "RE" reaction is a rearrangement of $\mathrm{NCH}_{3}$ to methanimine $\left(\mathrm{NHCH}_{2}\right)$. 


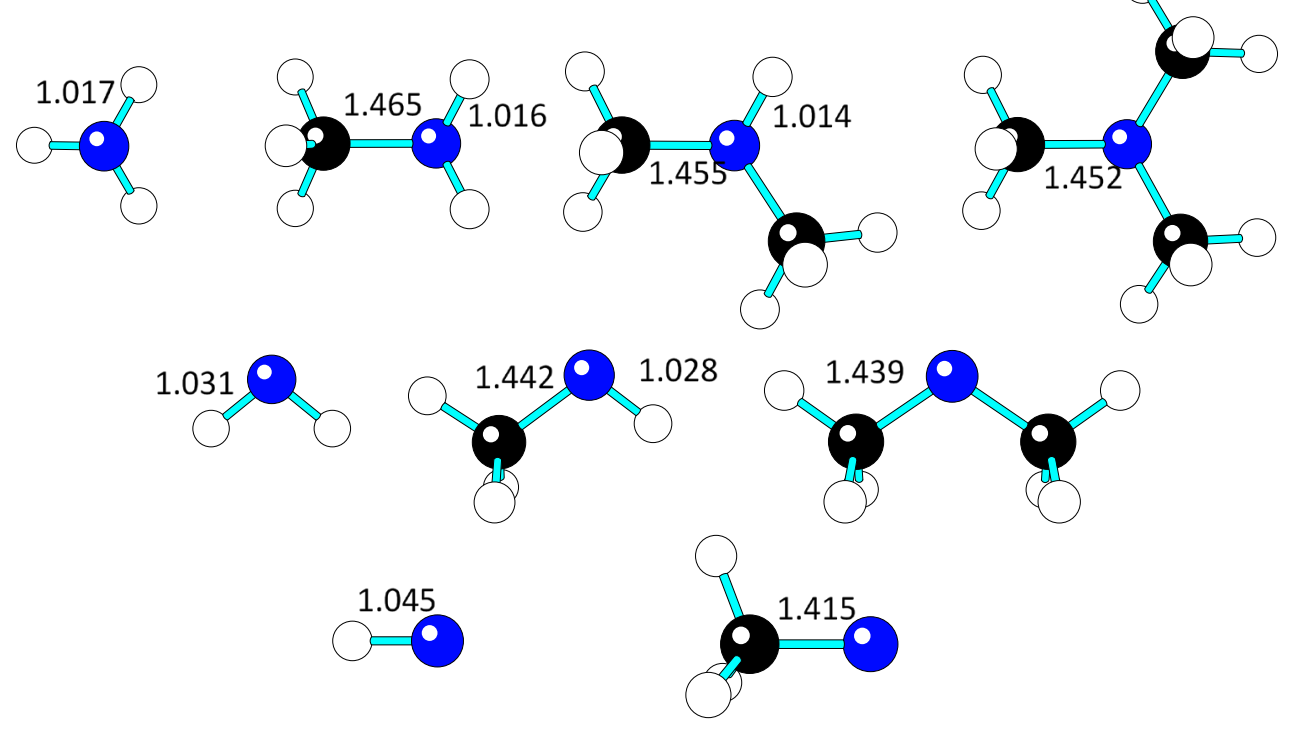

Figure 1: Optimized geometries and bond lengths in Ångström for $\mathrm{NH}_{\mathrm{x}}\left(\mathrm{CH}_{3}\right)_{\mathrm{n}-\mathrm{x}}(\mathrm{n}=3,2,1)$ Blue atoms are nitrogen, black are carbon and white are hydrogen.

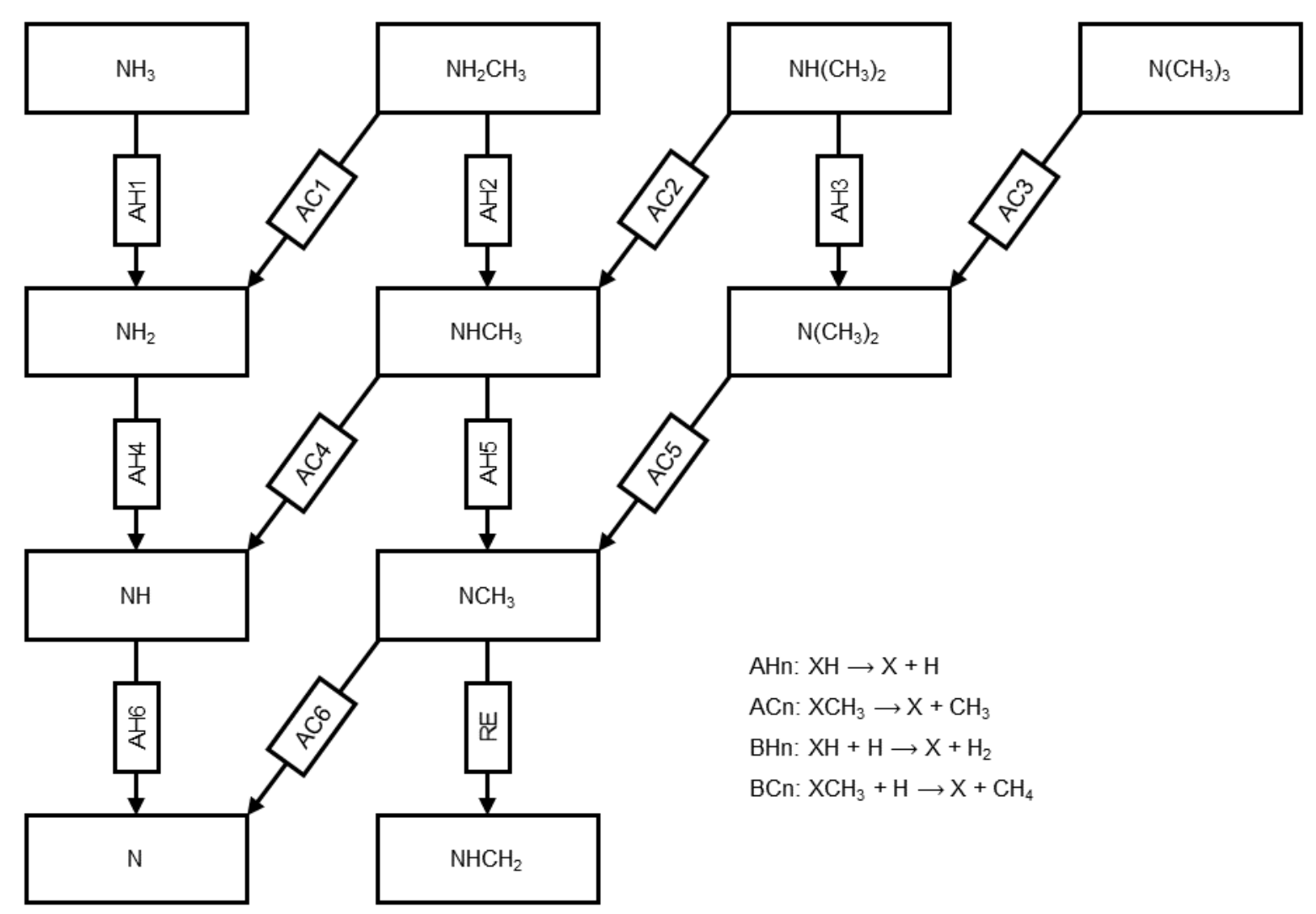

Scheme 1 - Decomposition pathways for the unimolecular decomposition of methyl amines, $\mathrm{NH}_{3-\mathrm{x}}\left(\mathrm{CH}_{3}\right)_{\mathrm{x}}$ with $\mathrm{x}=0-3$. Reactions labeled "AHn" release a hydrogen radical while reactions labeled "ACn" release a methyl radical. Reaction "RE" is a rearrangement. 
The energies of the unimolecular decompositions of ammonia and the three methylamines are presented Table 1 and graphically in Figs. S3-S4. All reactions are endoenergetic $\left(\Delta_{\mathrm{r}} \mathrm{E}^{\text {elec }}>0\right)$ and endothermic $\left(\Delta_{\mathrm{r}} \mathrm{H}^{\circ}>0\right)$. All reactions except methyl elimination from $\mathrm{N}\left(\mathrm{CH}_{3}\right)_{3}(\mathrm{AC} 3)$ are also endergonic $\left(\Delta_{\mathrm{r}} \mathrm{G}^{\circ}>0\right)$, making the reactants more favorable than the decomposition products. The free energies are lower at elevated temperatures due to an increase in entropy, making the difference between $\Delta_{\mathrm{r}} \mathrm{H}^{\circ}$ and $\Delta_{\mathrm{r}} \mathrm{G}^{\circ}$ larger at higher temperatures. In general, the reaction free energy is lower for a loss of methyl than for the loss of a hydrogen radical and the energy difference increases at higher temperatures, which is in line with the bond energies. The triplet spin state of $\mathrm{NCH}_{3}$ has a lower energy than the singlet state, but the molecule can undergo rearrangement $(\mathrm{RE})$ to the much more stable methanimine $\left(\mathrm{NHCH}_{2}\right)$ by migration of a hydrogen from the methyl to the nitrogen, thereby forming a nitrogen-carbon double bond. The structures of these molecules are given in Fig. S5 in the supporting information. The calculated N-C bond length is consistent with the formation of a double bond. This rearrangement was exothermic and had a negative reaction free energy at both STP and CVD conditions at all temperatures. The temperature dependence of the free energy is very small due to the entropy change being small for an internal rearrangement. 
Table 1: Reaction enthalpies and free energies for unimolecular decomposition of ammonia and methylamines at CVD conditions; i.e. temperatures in the range $300-1300^{\circ} \mathrm{C}$ and a total pressure of $50 \mathrm{mbar}$. All energies are given in $\mathrm{kJ} / \mathrm{mol}$. Reaction indices refer to Scheme 1.

\begin{tabular}{|c|c|c|c|c|c|c|c|c|c|c|c|c|}
\hline \multirow{2}{*}{$\begin{array}{l}\text { React } \\
\text { ion } \\
\text { index }\end{array}$} & \multicolumn{6}{|l|}{$\Delta_{\mathrm{r}} \mathrm{H}^{\circ}$} & \multicolumn{6}{|l|}{$\Delta_{\mathrm{r}} \mathrm{G}^{\circ}$} \\
\hline & \multicolumn{6}{|c|}{$300^{\circ} \mathrm{C} 500^{\circ} \mathrm{C} 700^{\circ}$} & \multicolumn{6}{|c|}{$300^{\circ} \mathrm{C} 500^{\circ} \mathrm{C} 700^{\circ} \mathrm{C} 900^{\circ} \mathrm{C} 1100^{\circ} \mathrm{C} 1300^{\circ} \mathrm{C}$} \\
\hline AH1 & 451.2 & 453.7 & 455.6 & 457.1 & 458.1 & 458.9 & 368.7 & 339.4 & 309.6 & 279.5 & 249.1 & 218.6 \\
\hline AH2 & 419.1 & 421.6 & 423.5 & 424.9 & 426.0 & 426.7 & 330.1 & 298.6 & 266.5 & 234.1 & 201.5 & 168.7 \\
\hline AH3 & 395.0 & 397.6 & 399.5 & 400.9 & 401.9 & 402.6 & 299.8 & 266.2 & 232.0 & 197.4 & 162.6 & 127.7 \\
\hline AH4 & 391.8 & 394.4 & 396.5 & 398.3 & 399.9 & 401.1 & 313.9 & 286.3 & 258.0 & 229.4 & 200.5 & 171.3 \\
\hline AH5 & 357.1 & 358.8 & 360.1 & 361.1 & 361.7 & 362.1 & 276.0 & 247.5 & 218.5 & 189.3 & 159.9 & 130.5 \\
\hline AH6 & 338.4 & 340.8 & 343.0 & 345.1 & 347.0 & 348.7 & 269.7 & 245.3 & 220.3 & 194.9 & 169.2 & 143.1 \\
\hline AC1 & 354.5 & 355.0 & 354.2 & 352.6 & 350.6 & 348.2 & 242.9 & 203.8 & 164.8 & 126.1 & 87.6 & 49.4 \\
\hline AC2 & 340.5 & 340.7 & 339.7 & 338.0 & 335.8 & 333.3 & 219.7 & 177.4 & 135.3 & 93.4 & 51.9 & 10.7 \\
\hline AC3 & 329.2 & 329.2 & 328.1 & 326.3 & 324.1 & 321.5 & 199.9 & 154.7 & 109.7 & 65.0 & 20.6 & -23.4 \\
\hline AC4 & 327.2 & 327.8 & 327.2 & 326.1 & 324.5 & 322.6 & 226.7 & 191.5 & 156.3 & 121.3 & 86.6 & 52.0 \\
\hline AC5 & 302.6 & 302.0 & 300.4 & 298.2 & 295.7 & 292.9 & 195.9 & 158.7 & 121.8 & 85.3 & 49.2 & 13.5 \\
\hline AC6 & 308.5 & 309.8 & 310.2 & 310.1 & 309.7 & 309.2 & 220.4 & 189.4 & 158.2 & 127.0 & 95.8 & 64.7 \\
\hline RE & -226.0 & -226.6 & -227.2 & -227.8 & -228.3 & -228.7 & -223.4 & -222.4 & -221.2 & -220.0 & -218.6 & -217.1 \\
\hline
\end{tabular}

In addition to unimolecular decomposition, there also exists a possibility for ammonia and methylamines to decompose via hydrogen radical assisted abstraction. Hydrogen radicals are abundant under typical CVD conditions given the high temperatures and carrier gas mixture used. ${ }^{31}$ The bimolecular decomposition reactions also follow Scheme 1 with the difference that a hydrogen radical is included as a co-reactant and reacts to form molecular dihydrogen or methane as co-products. The energies of the bimolecular decompositions of ammonia and the three methylamines are given in Table 2 and graphically in Figs. S3-S4. All reactions except the abstraction of a hydrogen from ammonia are exothermic and exergonic $\left(\Delta_{\mathrm{r}} \mathrm{G}^{\circ}<0\right)$ at all investigated CVD temperatures. As in the unimolecular case, the effect of increased temperature lowers the reaction enthalpy and free energy. Temperature effects are smaller than 
for the unimolecular decomposition due to the smaller change in entropy, since the number of reactants and products are the same. The reaction energy for the removal of a ligand is, as in the unimolecular case, lower for the methyl than the hydrogen.

The mechanism for hydrogen abstraction was assumed to be that initially a hydrogen atom can approach either a hydrogen bonded to the nitrogen or a methyl ligand. As the hydrogen approaches the ligand the bond to the nitrogen is elongated and the ligand can be released in the form of a dihydrogen or methane molecule. Transition states for th mechanism were found, and the corresponding activation energies were computed for the first bimolecular decomposition; the enthalpy and free energy of the transition states relative to the reactants are listed in Table 3 and graphically in Figs. S3-S4. The activation enthalpies for all transition states show very little variance within the temperature range used for CVD, while the activation free energy increases with increased temperature. Noteworthy is that the free energy barrier of hydrogen elimination depends strongly on the number of methyl ligands, while the barrier for the elimination of methane is fairly constant for all the methylamines. The barrier for hydrogen elimination is also lower than the barrier for methane elimination, making the hydrogen elimination the preferred kinetic path, while the reaction free energy makes the methane elimination the preferred thermodynamic path. 
Table 2: Reaction enthalpies and free energies for bimolecular decomposition of ammonia and methylamines at CVD conditions of $300-1300^{\circ} \mathrm{C}$ and 50 mbar. The bimolecular decomposition reactions follow Scheme 1 with the difference that a hydrogen radical is included as a coreactant and reacts to form molecular hydrogen or methane as a co-product. All energies are given in $\mathrm{kJ} / \mathrm{mol}$.

\begin{tabular}{|c|c|c|c|c|c|c|c|c|c|c|c|c|}
\hline \multirow{3}{*}{$\begin{array}{l}\text { Reaction } \\
\text { index }\end{array}$} & \multicolumn{6}{|l|}{$\Delta_{\mathrm{r}} \mathrm{H}^{\circ}$} & \multicolumn{6}{|l|}{$\Delta_{\mathrm{r}} \mathrm{G}^{\circ}$} \\
\hline & $300^{\circ} \mathrm{C}$ & $500^{\circ} \mathrm{C}$ & $700^{\circ} \mathrm{C}$ & $900^{\circ} \mathrm{C}$ & $1100^{\circ}$ & $1300^{\circ}$ & $300^{\circ} \mathrm{C}$ & $500^{\circ} \mathrm{C}$ & $700^{\circ} \mathrm{C}$ & $900^{\circ} \mathrm{C}$ & $1100^{\circ}$ & $1300^{\circ}$ \\
\hline & & & & & C & C & & & & & C & C \\
\hline BH1 & 10.4 & 10.4 & 9.9 & 9.0 & 7.9 & 6.6 & 3.6 & 1.1 & -1.2 & -3.4 & -5.4 & -7.3 \\
\hline ВН2 & -21.7 & -21.7 & -22.2 & -23.1 & -24.3 & -25.6 & -35.0 & -39.7 & -44.3 & -48.8 & -53.0 & -57.1 \\
\hline BH3 & -45.8 & -45.7 & -46.3 & -47.2 & -48.4 & -49.8 & -65.3 & -72.1 & -78.9 & -85.5 & -91.9 & -98.2 \\
\hline BH4 & -49.0 & -48.9 & -49.2 & -49.7 & -50.4 & -51.2 & -51.2 & -52.0 & -52.8 & -53.5 & -54.1 & -54.5 \\
\hline BH5 & -83.7 & -84.5 & -85.6 & -87.0 & -88.5 & -90.2 & -89.1 & -90.8 & -92.3 & -93.6 & -94.6 & -95.4 \\
\hline ВH6 & -102.4 & -102.5 & -102.7 & -103.0 & -103.3 & -103.6 & $\mid-95.4$ & -93.0 & -90.5 & -87.9 & -85.4 & -82.7 \\
\hline BC1 & -88.8 & -91.4 & -94.4 & -97.4 & -100.5 & -103.4 & -101.5 & -105.5 & -108.8 & -111.4 & -113.6 & -115.3 \\
\hline BC2 & -102.8 & -105.7 & -108.8 & -112.0 & -115.2 & -118.3 & -124.7 & -131.9 & -138.3 & -144.1 & -149.3 & -154.0 \\
\hline BC3 & -114.1 & -117.2 & -120.4 & -123.7 & -126.9 & -130.1 & -144.4 & -154.6 & -163.9 & -172.5 & -180.5 & -188.1 \\
\hline BC4 & -116.1 & -118.6 & -121.3 & -124.0 & -126.6 & -129.0 & -117.6 & -117.8 & -117.2 & -116.1 & -114.6 & -112.7 \\
\hline BC5 & -140.7 & -144.4 & -148.2 & -151.8 & -155.3 & -158.7 & -148.5 & -150.6 & -151.8 & -152.2 & -151.9 & -151.2 \\
\hline BC6 & -134.8 & -136.6 & -138.4 & -140.0 & -141.3 & -142.4 & -124.0 & -119.9 & -115.4 & -110.5 & -105.4 & -100.0 \\
\hline
\end{tabular}


Table 3: Activation enthalpies and free energies for bimolecular decomposition, listed in Table 2, at CVD conditions $\left(300-1300^{\circ} \mathrm{C}\right.$ and $\left.50 \mathrm{mbar}\right)$. All energies are given in $\mathrm{kJ} / \mathrm{mol}$.

\begin{tabular}{|c|c|c|c|c|c|c|c|c|c|c|c|c|}
\hline \multirow{2}{*}{$\begin{array}{l}\text { React } \\
\text { ion } \\
\text { index }\end{array}$} & \multicolumn{6}{|l|}{$\Delta^{\ddagger} \mathrm{H}$} & \multicolumn{6}{|l|}{$\Delta^{\ddagger} \mathrm{G}$} \\
\hline & \multicolumn{6}{|c|}{$300^{\circ} \mathrm{C} 500^{\circ} \mathrm{C} 700^{\circ} \mathrm{C} 900^{\circ} \mathrm{C} 1100^{\circ} \mathrm{C} 1300^{\circ} \mathrm{C}$} & \multicolumn{6}{|c|}{$300^{\circ} \mathrm{C} 500^{\circ} \mathrm{C} 700^{\circ} \mathrm{C} 900^{\circ} \mathrm{C} 1100^{\circ} \mathrm{C} 1300^{\circ} \mathrm{C}$} \\
\hline BH1 & 52.8 & 52.2 & 51.9 & 51.8 & 51.7 & 51.5 & 124.9 & 150.2 & 175.6 & 201.0 & 226.4 & 251.9 \\
\hline BH2 & 34.6 & 34.1 & 34.0 & 33.9 & 33.8 & 33.6 & 106.5 & 131.6 & 156.9 & 182.2 & 207.4 & 232.7 \\
\hline BH3 & 20.0 & 19.7 & 19.6 & 19.6 & 19.4 & 19.3 & 91.3 & 116.3 & 141.3 & 166.3 & 191.3 & 216.3 \\
\hline BC1 & 132.9 & 132.3 & 131.7 & 131.0 & 130.2 & 129.5 & 204.4 & 229.4 & 254.6 & 280.0 & 305.4 & 331.0 \\
\hline BC2 & 131.7 & 131.1 & 130.4 & 129.7 & 128.9 & 128.1 & 203.2 & 228.3 & 253.5 & 278.8 & 304.3 & 329.9 \\
\hline BC3 & 127.6 & 127.0 & 126.3 & 125.6 & 124.8 & 124.0 & 198.8 & 223.7 & 248.8 & 274.0 & 299.4 & 324.9 \\
\hline
\end{tabular}

\section{Adduct formation between $\mathrm{NH}_{3-x}\left(\mathrm{CH}_{3}\right)_{x}$ and $\mathrm{Ga}\left(\mathrm{CH}_{3}\right)_{3}$}

The adduct formation between $\mathrm{Ga}\left(\mathrm{CH}_{3}\right)_{3}$ and the methylamines with subsequent alkane release reactions are summarized in Scheme 2. The reaction energies are given in Table 4 and graphically in Figs. S3-S4. The adduct formation reactions (CAn) are all exothermic and exergonicat STP but endergonic for all reactions at CVD temperatures and pressures. The reaction free energy increases as the temperature is increased due to the decrease in entropy from the formed adducts. The reaction free energy for the three first reactions (CA1-3) decreases with increased number of methyl ligands on the nitrogen, possibly due to a stabilizing effect of the positive charge at the nitrogen by the methyl groups. For the last adduct reaction (CA4), the reaction free energy increases, possibly as an effect of steric factors. The optimized geometries for the adducts are given in Fig S6 in the supporting information.

The removal of ligands from the adducts is categorized in two groups: the release of methane $(\mathrm{CMn})$ and release of ethane (CEn). At STP and lower CVD temperatures, the removal of both methane and ethane are endothermic and at higher temperatures they are exothermic, except for CE1 which is exothermic at all temperatures. The temperature at which the enthalpy changes sign increases with increasing number of methyl ligands on the nitrogen atom. The reaction free energy is negative for all the removal reactions, and due to the increase in entropy, the reaction is more favorable at higher temperatures. As with the reaction entropy, the reaction free energy is lower for the removal of ethane than for the removal of methane for the mono- and dimethylamine adducts. The sum reaction of adduct formation plus the release of methane or ethane are exothermic at all calculated temperatures; at STP and lower CVD temperatures, the 
reaction free energy is negative. Although the release reactions are entropically favorable, the total reaction $(\mathrm{CAx}+\mathrm{CMy} / \mathrm{CEy})$ has a decrease in entropy. This indicates that the entropy loss in the formation of the adducts is larger than the entropy gain from release of an alkane. This makes the sum reactions less favorable at higher temperatures. The driving force for the adduct formation and release of methane and ethane is the release reactions. The formation of adducts between $\mathrm{NH}_{3-\mathrm{x}}\left(\mathrm{CH}_{3}\right)_{\mathrm{x}}$ and $\mathrm{Al}\left(\mathrm{CH}_{3}\right)_{3}$ follows the same trends as the adduct formation with $\mathrm{Ga}\left(\mathrm{CH}_{3}\right)_{3}$; all details for adduct formation with $\mathrm{Al}\left(\mathrm{CH}_{3}\right)_{3}$ are given in the supporting information.

The alkane release mechanism from the adduct contains a migration of either a hydrogen (methane release) or a methyl (ethane release) from the nitrogen towards one of the methyl groups of $\mathrm{Ga}\left(\mathrm{CH}_{3}\right)_{3}$. Simultaneously the nitrogen and gallium atoms are pulled closer to form a covalent bond. The transition state barriers for the alkane release reactions are given in Table 5 and graphically in Figs. S3-S4. The transition state enthalpy is almost constant for all reactions in the CVD temperature range and does also not depend on the number of methyl groups on the nitrogen. The activation enthalpy for the elimination of methane is lower than for the elimination of ethane. The activation free energy barrier of the eliminations has a higher dependence on temperature than the activation enthalpy has, except for reactions CM1 and CE3, and increases slightly with increasing temperatures. The activation free energy of methyl eliminations shows a larger dependence on the number of methyl ligands than the activation free energy of ethane eliminations does. As with the enthalpy barrier, the free energy barrier is higher for the elimination of ethane than for methane, demonstrating that the expected rate of ethane elimination is slower than the rate of methane elimination. 


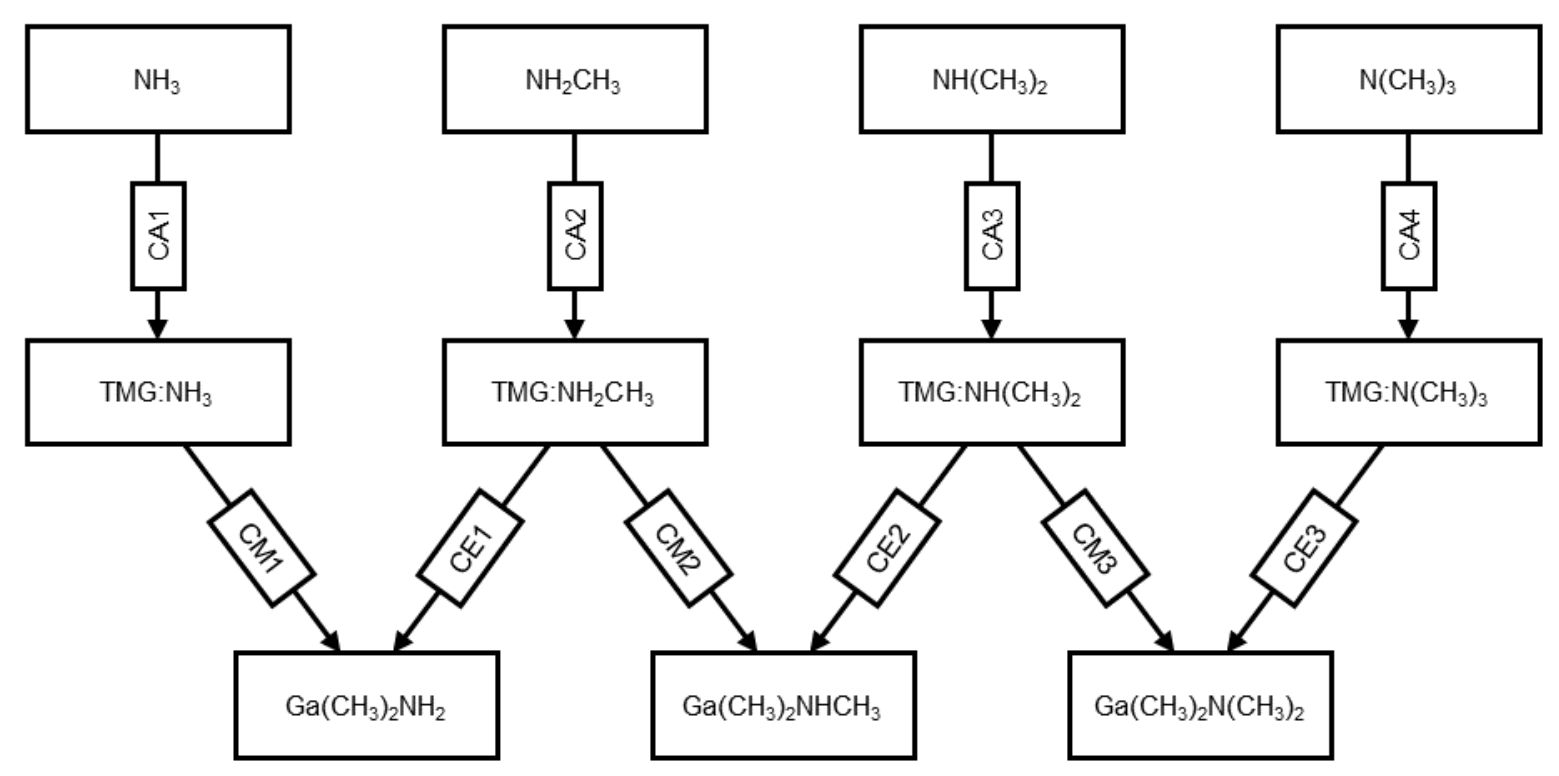

Scheme 2: Reaction pathway diagram of the adduct formation between $\mathrm{NH}_{3-\mathrm{x}}\left(\mathrm{CH}_{3}\right)_{\mathrm{x}}$ and $\mathrm{Ga}\left(\mathrm{CH}_{3}\right)_{3}$ and subsequent alkane elimination reactions. Reactions $\mathrm{CAn}$ are the adduct formation, CMn are the release of methane, and CEn are the release of ethane. 
Table 4: Reaction enthalpies and free energies for adduct formation between $\mathrm{NH}_{3-\mathrm{x}}\left(\mathrm{CH}_{3}\right)_{\mathrm{x}}$ and $\mathrm{Ga}\left(\mathrm{CH}_{3}\right)_{3}$ and subsequent alkane elimination reactions at $\mathrm{CVD}$ conditions: $300^{\circ} \mathrm{C}-1300^{\circ} \mathrm{C}$ and 50 mbar. All energies are given in $\mathrm{kJ} / \mathrm{mol}$. Reaction indices refer to Scheme 2.

\begin{tabular}{|c|c|c|c|c|c|c|c|c|c|c|c|c|}
\hline \multirow{2}{*}{$\begin{array}{l}\text { Reaction } \\
\text { index }\end{array}$} & \multicolumn{6}{|l|}{$\Delta_{\mathrm{r}} \mathrm{H}^{\circ}$} & \multicolumn{6}{|l|}{$\Delta_{\mathrm{r}} \mathrm{G}^{\circ}$} \\
\hline & $300^{\circ} \mathrm{C}$ & $500^{\circ} \mathrm{C}$ & $700^{\circ} \mathrm{C}$ & $900^{\circ} \mathrm{C}$ & $1100^{\circ} \mathrm{C}$ & $1300^{\circ} \mathrm{C}$ & $300^{\circ} \mathrm{C}$ & $500^{\circ} \mathrm{C}$ & $700^{\circ} \mathrm{C}$ & $900^{\circ} \mathrm{C}$ & $1100^{\circ} \mathrm{C}$ & $1300^{\circ} \mathrm{C}$ \\
\hline CA1 & -73.6 & -72.4 & -71.0 & -69.5 & -67.9 & -66.4 & 53.9 & 98.3 & 142.3 & 185.9 & 229.4 & 272.6 \\
\hline CA2 & -83.0 & -80.1 & -77.0 & -73.9 & -70.7 & -67.4 & 36.6 & 77.9 & 118.5 & 158.3 & 197.7 & 236.5 \\
\hline CA3 & -91.7 & -88.7 & -85.6 & -82.4 & -79.2 & -76.0 & 27.4 & 68.5 & 108.8 & 148.4 & 187.5 & 226.1 \\
\hline CA4 & -95.5 & -92.3 & -89.2 & -86.1 & -83.0 & -79.8 & 35.0 & 80.1 & 124.3 & 167.9 & 211.0 & 253.5 \\
\hline CM1 & 1.2 & -0.2 & -1.7 & -3.3 & -4.9 & -6.6 & -98.2 & -132.7 & -166.8 & -200.6 & -234.1 & -267.4 \\
\hline CM2 & 7.6 & 4.4 & 1.1 & -2.2 & -5.5 & -8.8 & -77.0 & -106.0 & -134.1 & -161.6 & -188.5 & -214.9 \\
\hline CM3 & 9.8 & 4.8 & -0.2 & -5.2 & -10.1 & -15.0 & -60.5 & -84.3 & -106.7 & -128.2 & -148.7 & -168.6 \\
\hline CE1 & -20.5 & -23.4 & -26.5 & -29.7 & -33.0 & -36.3 & -119.7 & -153.9 & -187.3 & -220.1 & -252.3 & -284.0 \\
\hline CE2 & 3.4 & 0.0 & -3.4 & -6.9 & -10.3 & -13.6 & $\mid-91.1$ & -123.6 & -155.2 & -186.0 & -216.3 & -246.1 \\
\hline CE3 & 13.4 & 8.0 & 2.8 & -2.4 & -7.4 & -12.5 & -81.1 & -113.3 & -144.0 & -173.7 & -202.5 & -230.5 \\
\hline
\end{tabular}

Table 5: Activation enthalpies and free energies for alkane elimination from the adducts at CVD conditions: $300-1300^{\circ} \mathrm{C}$ and 50 mbar. All energies are given in $\mathrm{kJ} / \mathrm{mol}$. Reaction indices refer to Scheme 2.

\begin{tabular}{|l|llllll|lllllll|}
\hline $\begin{array}{l}\text { Reaction } \\
\text { index }\end{array}$ & $\Delta^{\ddagger} \mathrm{H}$ & \multicolumn{1}{|l|}{$\Delta^{\ddagger} \mathrm{G}$} \\
\cline { 2 - 11 } & $300^{\circ} \mathrm{C}$ & $500^{\circ} \mathrm{C}$ & $700^{\circ} \mathrm{C}$ & $900^{\circ} \mathrm{C}$ & $1100^{\circ} \mathrm{C}$ & $1300^{\circ} \mathrm{C}$ & $300^{\circ} \mathrm{C}$ & $500^{\circ} \mathrm{C}$ & $700^{\circ} \mathrm{C}$ & $900^{\circ} \mathrm{C}$ & $1100^{\circ} \mathrm{C}$ & $1300^{\circ} \mathrm{C}$ \\
\hline CM1 & 144.8 & 145.8 & 146.8 & 147.8 & 148.7 & 149.4 & 145.2 & 146.2 & 146.6 & 146.7 & 146.5 & 146.2 \\
CM2 & 146.2 & 145.5 & 144.9 & 144.2 & 143.4 & 142.5 & 151.4 & 155.5 & 158.8 & 162.4 & 166.0 & 169.8 \\
CM3 & 148.0 & 147.3 & 146.6 & 145.9 & 145.1 & 144.2 & 153.8 & 158.5 & 162.2 & 166.2 & 170.2 & 174.5 \\
& & & & & & & & & & & & \\
CE1 & 386.6 & 387.1 & 386.8 & 386.1 & 385.0 & 383.8 & 389.4 & 392.8 & 394.8 & 396.9 & 399.0 & 401.3 \\
CE2 & 392.4 & 392.4 & 391.9 & 391.1 & 390.0 & 388.7 & 393.7 & 395.5 & 396.5 & 397.6 & 398.9 & 400.3 \\
CE3 & 388.2 & 388.0 & 387.3 & 386.4 & 385.3 & 384.0 & 388.0 & 388.1 & 388.1 & 388.2 & 388.5 & 388.9 \\
\hline
\end{tabular}




\section{Surface interactions with GaN (0001)}

Adsorption reactions for both $\mathrm{NH}_{3-\mathrm{x}}\left(\mathrm{CH}_{3}\right)_{\mathrm{x}}$ and their decomposition products were modeled by allowing the adsorbate to displace a hydrogen at a $\mathrm{GaN}$ surface site, releasing a hydrogen radical.

$$
\mathrm{H} \mathrm{H}+\mathrm{NH}_{\mathrm{x}-\mathrm{y}}\left(\mathrm{CH}_{3}\right)_{\mathrm{y}} \rightarrow \mathrm{HNH}_{\mathrm{x}-\mathrm{y}}\left(\mathrm{CH}_{3}\right)_{\mathrm{y}}+\mathrm{H} \cdot
$$

The reaction energies are presented in Table 6 and graphically in Figs. S3-S4; Fig. 2 shows the geometries for the adsorption of the intact $\mathrm{NH}_{3-\mathrm{x}}\left(\mathrm{CH}_{3}\right)_{\mathrm{x}}$ species on $\mathrm{GaN}(0001)$. In Table 6 the reactions are indexed as Dxy, where $\mathrm{x}$ is the total number of ligands attached to the nitrogen and $\mathrm{y}$ is the number of methyl ligands. Reaction DRE is the adsorption of the rearranged methanimine. While the adsorptions of $\mathrm{NH}_{3}$ and $\mathrm{NH}_{2} \mathrm{CH}_{3}$ are exothermic at the CVD temperatures, undecomposed $\mathrm{NH}\left(\mathrm{CH}_{3}\right)_{2}$ and $\mathrm{N}\left(\mathrm{CH}_{3}\right)_{3}$ have a positive reaction enthalpy. The adsorption of all undecomposed species has a positive free energy of adsorption at all CVD temperatures and thus these are not likely to adsorb significantly. The reaction free energy also increases with the temperature for adsorption of all undecomposed species. The computed $\mathrm{N}-$ Ga distances and geometries indicate that the adsorption of $\mathrm{N}\left(\mathrm{CH}_{3}\right)_{3}$ is hindered by steric repulsion due to the methyl groups.

For the first decomposition products, the adsorptions at CVD conditions are exothermic and exergonic, except for $\mathrm{N}\left(\mathrm{CH}_{3}\right)_{2}$ which is endergonic at high $\mathrm{CVD}$ temperature. A lower number of methyl groups on the nitrogen gives a lower adsorption free energy. At higher temperatures, the adsorptions have higher reaction free energies and the effect of temperature is larger as the number of methyl groups is increased. The overall lowest reaction free energy is for the

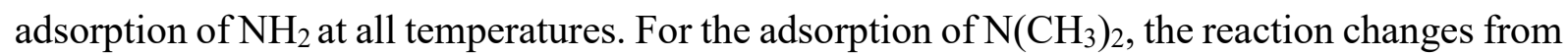
exergonic at lower temperatures to endergonic at temperatures between $900-1100^{\circ} \mathrm{C}$. All other reaction free energies are negative indicating favorable reactions.

As with the first decomposition products, all desorptions of second decomposition products are exothermic. The adsorption of $\mathrm{NH}$ and $\mathrm{NCH}_{3}$ are exergonic at lower $\mathrm{CVD}$ temperatures and $\mathrm{NCH}_{3}$ becomes endergonic above $900-1100^{\circ} \mathrm{C}$. The reaction free energy is higher for the adsorption of $\mathrm{NCH}_{3}$ than for $\mathrm{NH}$ at all CVD temperatures. The adsorption of the nitrogen radical is both exothermic and exergonic and is less favorable than the adsorption of NH but more favorable than the adsorption of $\mathrm{N}\left(\mathrm{CH}_{3}\right)$, though the free energy approaches that of $\mathrm{NH}$ as temperature is increased. The adsorption of $\mathrm{NHCH}_{2}$ is has an adsorption enthalpy close to zero at all CVD conditions and the high adsorption free energy makes adsorption unfavorable. 
A radical precursor species is necessary to allow exchange at the hydrogenated GaN surface. The reaction is more thermodynamically likely with a lower number of methyls (i.e., higher number of hydrogen bonded to the precursor nitrogen). In the CVD temperature range, the increase in $\Delta_{\mathrm{r}} \mathrm{G}$ is more significant for species with a greater number of methyl groups than for ammonia-derived gaseous reactants.
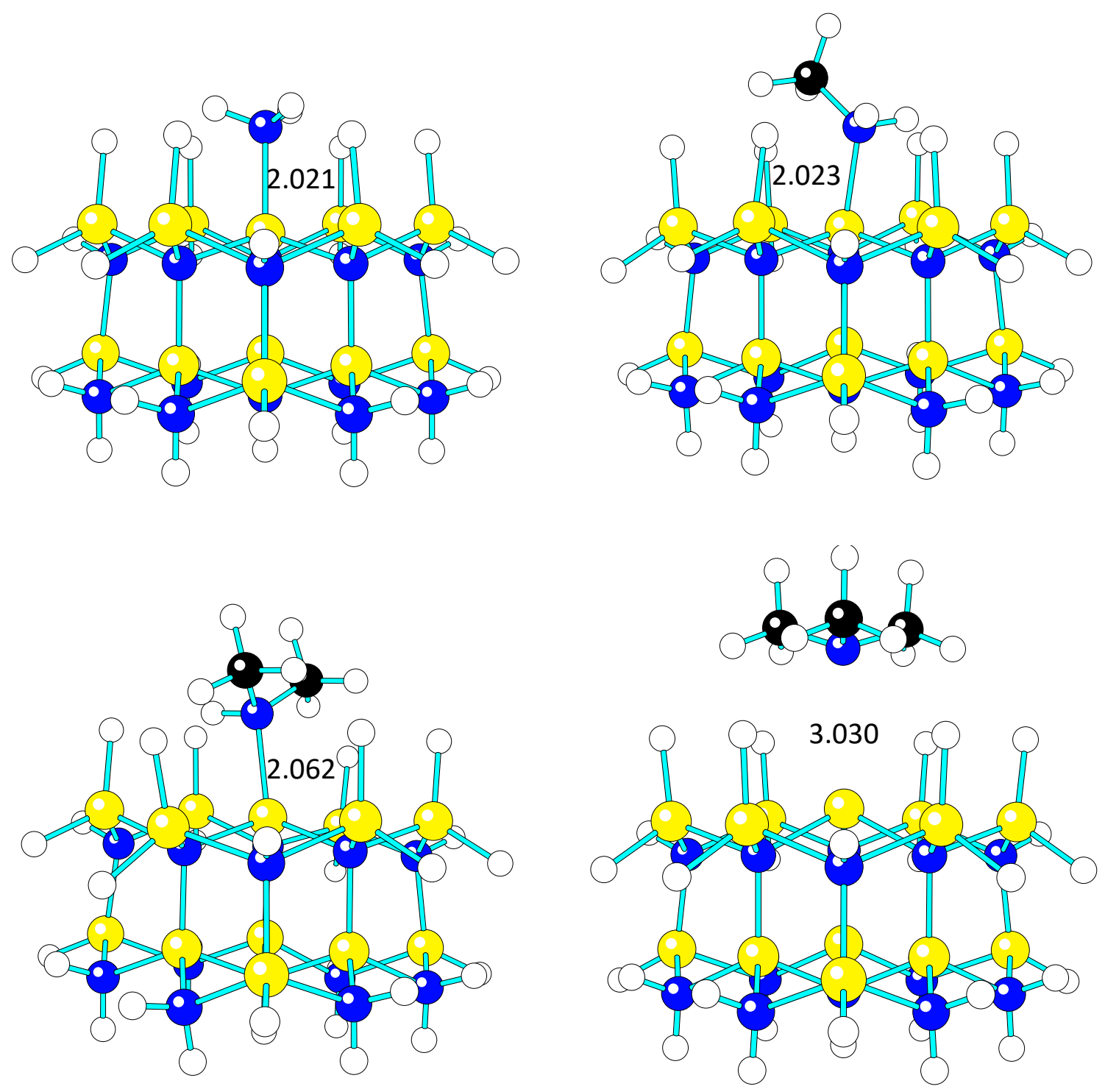

Figure 2: Optimized geometries for the D30 - D33 adsorptions of undecomposed precursors at the GaN (0001) surface. The distance between the Ga at the adsorption site and the $\mathrm{N}$ in the precursor is given in Ångströms. Yellow atoms are gallium, blue nitrogen, black carbon and white hydrogen. 
Table 6: Reaction enthalpies and free energies for the reaction of ammonia and methylamines with the $\mathrm{H}$-terminated $\mathrm{GaN}(0001)$ surface at $\mathrm{CVD}$ conditions $\left(300^{\circ} \mathrm{C}-1300^{\circ} \mathrm{C}\right.$ at $\left.50 \mathrm{mbar}\right)$. The reactions are indexed as Dxy, where $\mathrm{x}$ is the total number of ligands attached to the nitrogen and $\mathrm{y}$ is the number of methyl ligands. Reaction DRE is the adsorption of the rearranged methanimine. All values are given in $\mathrm{kJ} / \mathrm{mol}$.

\begin{tabular}{|c|c|c|c|c|c|c|c|c|c|c|c|c|}
\hline & \multicolumn{6}{|l|}{$\Delta_{\mathrm{r}} \mathrm{H}^{\circ}$} & \multicolumn{6}{|l|}{$\Delta_{\mathrm{r}} \mathrm{G}^{\circ}$} \\
\hline & \multicolumn{2}{|c|}{$300^{\circ} \mathrm{C} 500^{\circ} \mathrm{C}$} & \multirow[t]{2}{*}{$700^{\circ} \mathrm{C}$} & \multirow[t]{2}{*}{$900^{\circ} \mathrm{C}$} & \multirow{2}{*}{$\begin{array}{l}1100^{\circ} \\
\mathrm{C}\end{array}$} & \multirow{2}{*}{$\begin{array}{l}1300^{\circ} \\
\mathrm{C}\end{array}$} & \multirow{2}{*}{\multicolumn{2}{|c|}{$300^{\circ} \mathrm{C} 500^{\circ} \mathrm{C}$}} & \multirow[t]{2}{*}{$700^{\circ} \mathrm{C}$} & \multirow[t]{2}{*}{$900^{\circ} \mathrm{C}$} & \multirow{2}{*}{$\begin{array}{l}1100^{\circ} \\
\mathrm{C}\end{array}$} & \multirow{2}{*}{$\begin{array}{l}1300^{\circ} \\
\mathrm{C}\end{array}$} \\
\hline & & & & & & & & & & & & \\
\hline D30 & -11.6 & -9.5 & -7.3 & -5.2 & -3.0 & -0.9 & 38.3 & 55.3 & 71.8 & 87.9 & 103.6 & 119.0 \\
\hline D31 & -24.0 & -23.3 & -22.7 & -22.2 & -21.8 & -21.3 & 49.6 & 75.2 & 100.6 & 125.8 & 151.0 & 176.2 \\
\hline D32 & 4.4 & 5.1 & 5.6 & 6.0 & 6.3 & 6.6 & 87.9 & 117.0 & 145.9 & 174.6 & 203.4 & 232.1 \\
\hline D33 & 79.8 & 79.6 & 78.9 & 77.8 & 76.6 & 75.3 & 144.1 & 166.6 & 189.1 & 211.9 & 234.8 & 258.0 \\
\hline D20 & -256.8 & -254.7 & -252.8 & -251.0 & -249.3 & -247.6 & -205.6 & -188.0 & -171.0 & -154.3 & -138.0 & -121.9 \\
\hline D21 & -228.6 & -226.6 & -224.8 & -223.1 & -221.4 & -219.7 & -163.2 & -140.7 & -118.7 & -97.1 & -75.7 & -54.6 \\
\hline D22 & -196.5 & -196.2 & -196.1 & -196.0 & -196.0 & -196.0 & -107.3 & -76.3 & -45.3 & -14.3 & 16.7 & 47.7 \\
\hline D10 & -201.4 & -201.7 & -202.2 & -202.8 & -203.5 & -204.2 & -148.6 & -130.2 & -111.6 & -93.0 & -74.2 & -55.3 \\
\hline D11 & -171.2 & -172.1 & -173.3 & -174.6 & -176.1 & -177.5 & -96.9 & -70.9 & -44.5 & -17.9 & 8.9 & 35.9 \\
\hline DRE & -3.7 & 0.0 & 3.1 & 5.7 & 8.1 & 10.3 & 38.3 & 52.3 & 65.4 & 78.0 & 90.1 & 101.9 \\
\hline D00 & -145.0 & -144.8 & -145.0 & -145.4 & -145.9 & -146.4 & -111.7 & -100.1 & -88.5 & -76.9 & -65.2 & -53.4 \\
\hline
\end{tabular}

In summary, the computational study shows that the gas phase chemistry for decomposition of $\mathrm{NH}_{3-\mathrm{x}}\left(\mathrm{CH}_{3}\right)_{\mathrm{x}}$ becomes more thermodynamically favorable with more methyl groups in the amine precursor. Adduct formation is more favorable with fewer methyl groups in the amine precursor, and the subsequent release of methane or ethane is less favorable as the number of methyl groups is increased. Overall, the gas phase chemistry becomes more favored with higher temperatures. The surface chemistry for adsorption of the $\mathrm{NH}_{3-\mathrm{x}}\left(\mathrm{CH}_{3}\right)_{\mathrm{x}}$ becomes more favorable for decomposition products with fewer methyl groups and with lower temperatures. This suggests that $\mathrm{N}\left(\mathrm{CH}_{3}\right)_{3}$ should be the best nitrogen precursor for gas phase chemistry rendering a higher concentration of more reactive species with less nitrogen species in adducts with gallium species. However, $\mathrm{NH}_{3}$ is the most favored nitrogen precursor for surface chemistry as 
the more methyl groups on the nitrogen atoms, the higher the steric hindrance for chemisorption seems to be.

\section{CVD experiments of $\mathrm{GaN}$ using $\mathrm{NH}_{3-x}\left(\mathrm{CH}_{3}\right)_{x}$ and $\mathrm{Ga}\left(\mathrm{CH}_{3}\right)_{3}$}

CVD of GaN was first undertaken with $\mathrm{NH}_{3}$ and $\mathrm{Ga}\left(\mathrm{CH}_{3}\right)_{3}$ to use as a reference. With a N/Ga ratio of 570 and reactor temperatures of $850{ }^{\circ} \mathrm{C}$ and $1000^{\circ} \mathrm{C}$, this process resulted in crystalline $\mathrm{GaN}$ films with somewhat rough surfaces (Fig. 3). The deposition rate was found to be 44 $\mathrm{nm} / \mathrm{min}$ at $1000^{\circ} \mathrm{C}$ and $37 \mathrm{~nm} / \mathrm{min}$ at $850^{\circ} \mathrm{C}$.
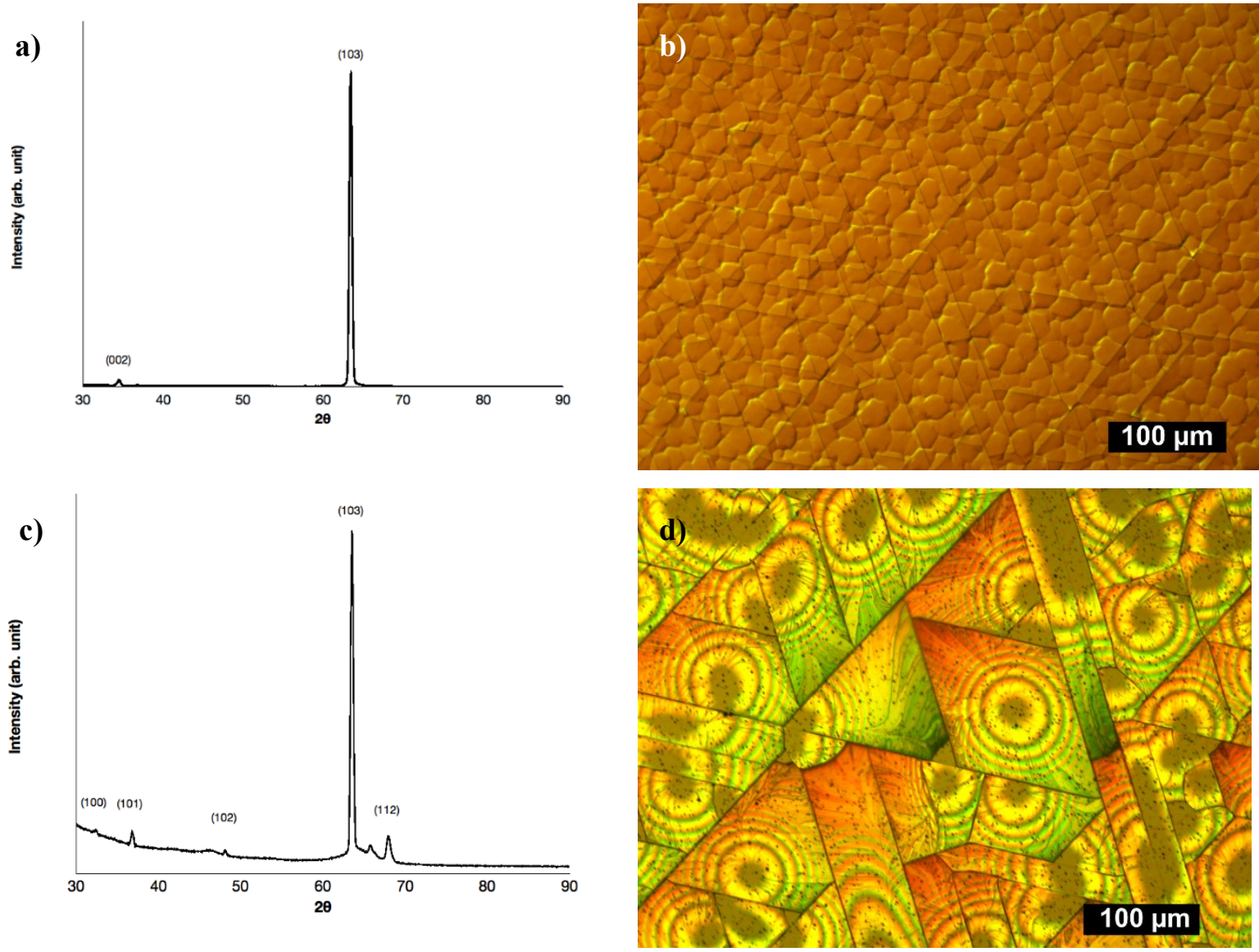

Figure 3: GaN films grown by $\mathrm{CVD}$ using $\mathrm{Ga}\left(\mathrm{CH}_{3}\right)_{3}$ and $\mathrm{NH}_{3}$ with $\mathrm{N} / \mathrm{Ga}=570$. Deposition at $1000{ }^{\circ} \mathrm{C}$ in panels a) and b) and at $850{ }^{\circ} \mathrm{C}$ in panels c) and d) afforded crystalline $\mathrm{GaN}$ films, as seen from GIXRD with a rough surface, imaged by optical microscopy.

The same experimental conditions with a reactor temperature of $1000^{\circ} \mathrm{C}$ and $\mathrm{N} / \mathrm{Ga}=570$ were then used for CVD experiments with $\mathrm{NH}_{2} \mathrm{CH}_{3}, \mathrm{NH}\left(\mathrm{CH}_{3}\right)_{2}$ and $\mathrm{N}\left(\mathrm{CH}_{3}\right)_{3}$. None of these amines yielded any film by SEM or XRD under these conditions. CVD experiments at $850{ }^{\circ} \mathrm{C}$ using 
$\mathrm{NH}_{2} \mathrm{CH}_{3}$ and $\mathrm{N}\left(\mathrm{CH}_{3}\right)_{3}$ with $\mathrm{N} / \mathrm{Ga}=570$ were performed to probe the possibility of lower $\mathrm{CVD}$ temperatures for $\mathrm{GaN}$ by $\mathrm{NH}_{3-\mathrm{x}}\left(\mathrm{CH}_{3}\right)_{\mathrm{x}}$. These experiments yielded $\mathrm{Ga}$ metal droplets (Fig. 4).
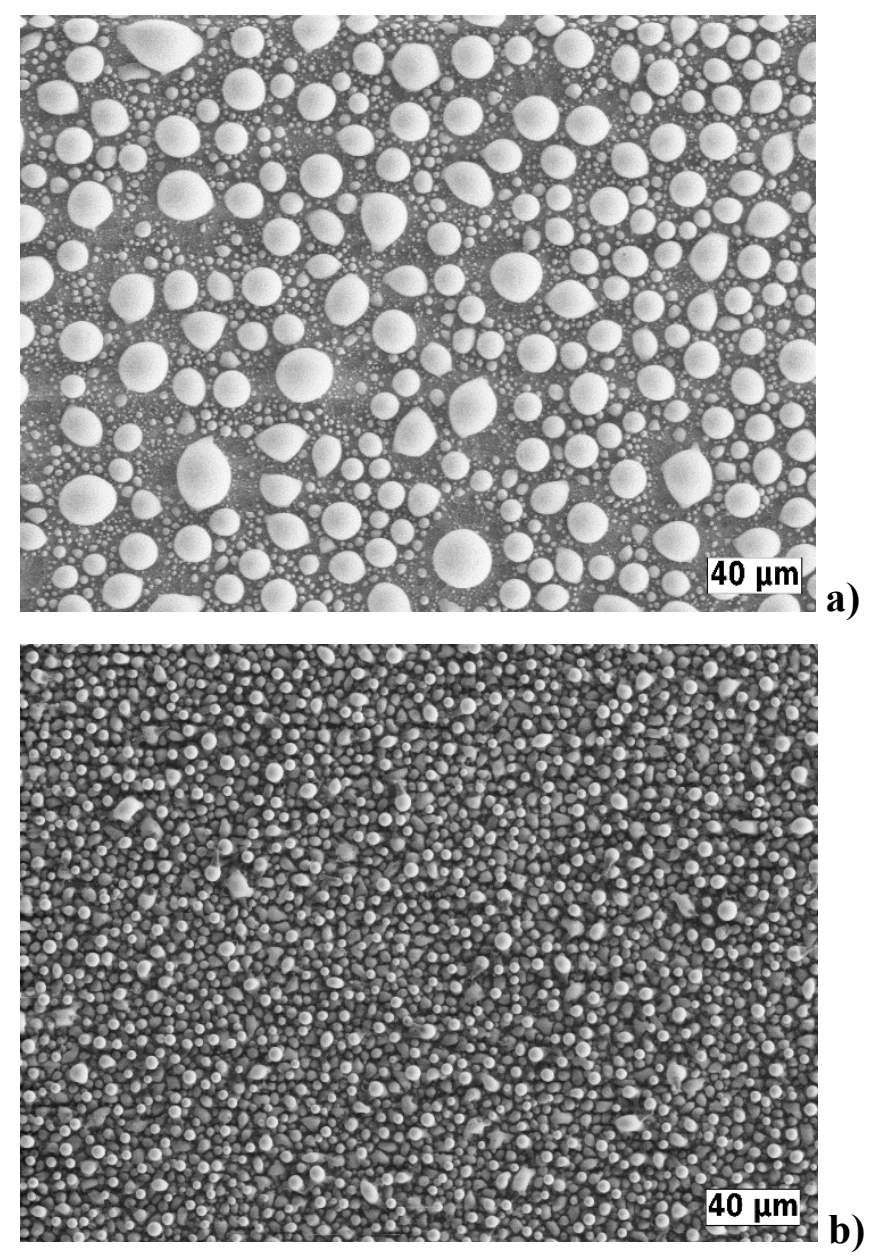

Figure 4: SEM surface micrographs from $\mathrm{CVD}$ samples grown at $850{ }^{\circ} \mathrm{C}$ using $\mathrm{Ga}\left(\mathrm{CH}_{3}\right)_{3}$ and a) $\mathrm{NH}_{2} \mathrm{CH}_{3}$ and b) $\mathrm{N}\left(\mathrm{CH}_{3}\right)_{3}$ using $\mathrm{N} / \mathrm{Ga}=570$.

Further attempts to form $\mathrm{GaN}$ were undertaken using $\mathrm{N}\left(\mathrm{CH}_{3}\right)_{3}$ and $\mathrm{Ga}\left(\mathrm{CH}_{3}\right)_{3}$ The N/Ga ratio was tuned by varying the flow of $\mathrm{N}\left(\mathrm{CH}_{3}\right)_{3}$ while keeping the flow of $\mathrm{Ga}\left(\mathrm{CH}_{3}\right)_{3}$ constant at an intermediate deposition temperature of $925{ }^{\circ} \mathrm{C}$. These experiments also resulted in the formation of droplets with the additional growth of cones (Fig. 5). The number of the droplets and cones varied with the $\mathrm{N} / \mathrm{Ga}$ ratio; a high $\mathrm{N} / \mathrm{Ga}$ ratio (i.e., higher flow of $\left.\mathrm{N}\left(\mathrm{CH}_{3}\right)_{3}\right)$ resulted in a lower density of droplets and cones as seen by SEM (Fig. 5). This was also seen by the naked eye as the samples from CVD with a lower N/Ga appeared greyer and more metallic than the samples from CVD with higher N/Ga, which had a shiny appearance on the transparent greenish SiC substrate. The grey coating on the samples could easily be scratched. From EDS (Fig. S8), the droplets were pure gallium, while the cones consisted of gallium with obvious 
amounts of nitrogen and carbon. GIXRD of the sample (Fig. S9) show an indication of crystalline gallium in its orthorhombic structure and possible weak XRD peaks from crystalline GaN.
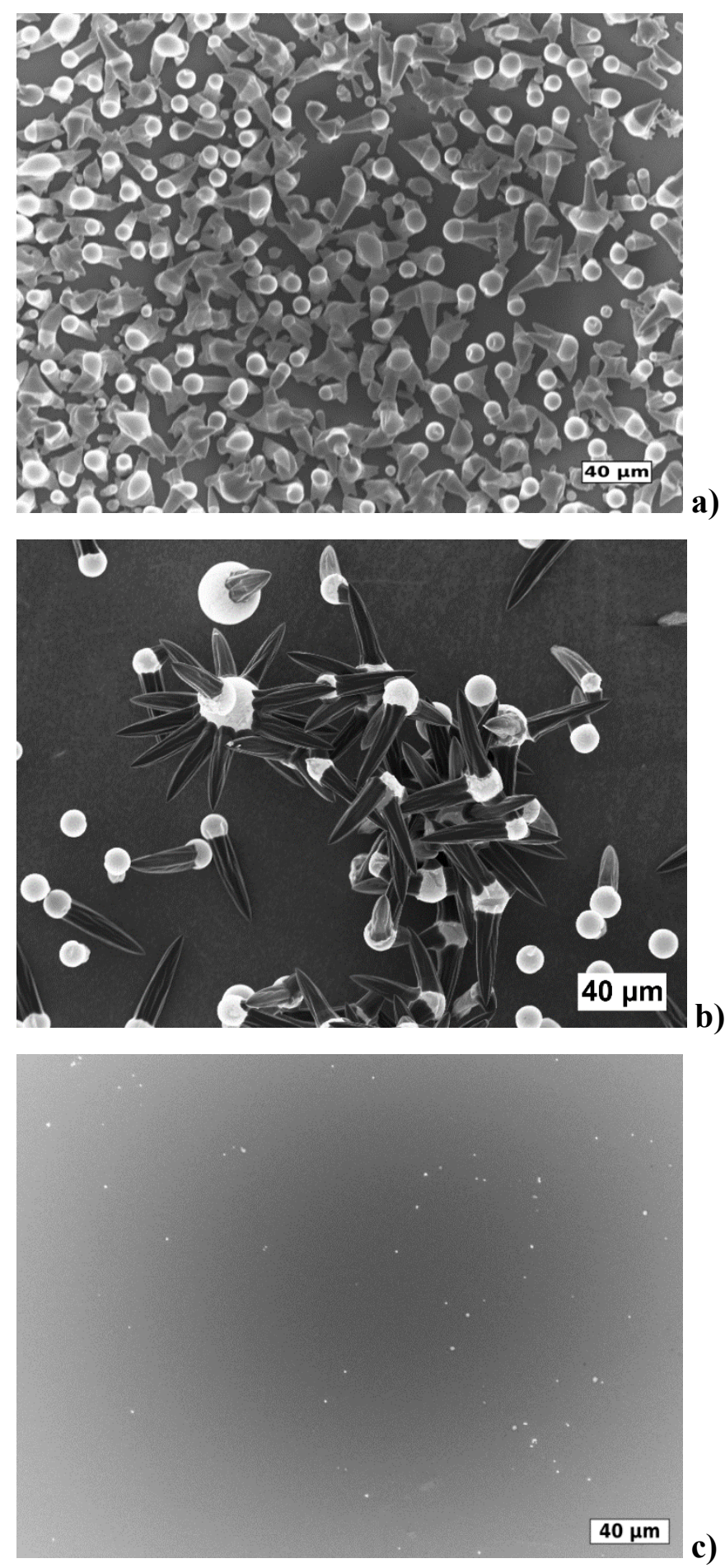

Figure 5: SEM surface micrographs from CVD samples grown at $925{ }^{\circ} \mathrm{C}$ from $\mathrm{Ga}\left(\mathrm{CH}_{3}\right)_{3}$ and $\mathrm{N}\left(\mathrm{CH}_{3}\right)_{3}$ using a) $\mathrm{N} / \mathrm{Ga}=275$, b) N/Ga $=570$ and c) $\mathrm{N} / \mathrm{Ga}=1100$. 
To further study how the concentration of amine affected the deposition, experiments with a $\mathrm{N} / \mathrm{Ga}$ fixed at 570 and changing the flows, and thereby the partial pressures, of both $\mathrm{N}\left(\mathrm{CH}_{3}\right)_{3}$ and $\mathrm{Ga}\left(\mathrm{CH}_{3}\right)_{3}$ were performed (Fig. 6). From these experiments a higher partial pressure of amine, coupled with a higher partial pressure of $\mathrm{Ga}\left(\mathrm{CH}_{3}\right)_{3}$, rendered larger droplets and fewer cones.
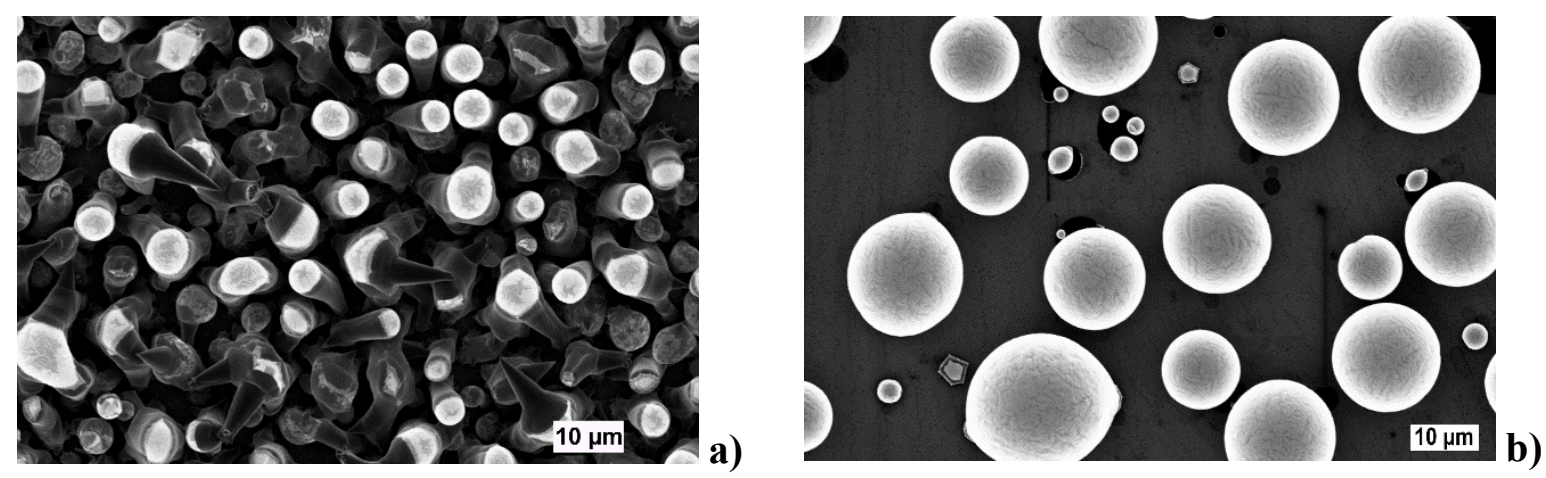

Figure 6: SEM surface micrographs from $\mathrm{CVD}$ samples grown at $925{ }^{\circ} \mathrm{C}$ using $\mathrm{Ga}\left(\mathrm{CH}_{3}\right)_{3}$ and $\mathrm{N}\left(\mathrm{CH}_{3}\right)_{3}$ with $\mathrm{N} / \mathrm{Ga}=570$ and a) low precursor flow $\left(\mathrm{N}\left(\mathrm{CH}_{3}\right)_{3}\right.$ at a partial pressure of 2 mbar) and b) high precursor flow $\left(\mathrm{N}\left(\mathrm{CH}_{3}\right)_{3}\right.$ at a partial pressure of 8 mbar).

\section{Discussion}

While the computational study shows that the amines will decompose more easily than ammonia and thereby be more abundant nitrogen precursors in the gas phase at thermodynamic equilibrium for CVD, the experimental study demonstrated that methylamines cannot replace ammonia in CVD of GaN. Rather, methylamines seem to be poor nitrogen precursors as no contiguous GaN films could be grown using them in this study. This is in line with the computational results that showed that methylamines interacted less favorably than amines with the GaN surface (i.e. higher $\Delta_{\mathrm{r}} \mathrm{G}$ in Table 6), suggesting that surface chemistry rather than gas phase chemistry is the limiting factor to growing high quality GaN films. Specifically, the exchange of an activated gas phase radical for a surface hydrogen shows less of a thermodynamic driving force as the number of methyl groups increase. This is not due to a difference in the N-H vs. N-Me bond strength (as was originally supposed), but rather due to a difference in radical chemisorption at a surface gallium site. Another factor to consider is that the bimolecular decomposition rates are lower for methylamines than for amines due to higher activation energies (Table 3), which make the methylamine precursor concentrations lower than expected if equilibrium has not been reached in the CVD process. It can also be noted that potentially detrimental adduct derivatives can be formed after both methane and ethane 
elimination (Scheme 2) for most of the $\mathrm{Ga}\left(\mathrm{CH}_{3}\right)_{3}$-methylamine adducts, but only by methane elimination for the $\mathrm{Ga}\left(\mathrm{CH}_{3}\right)_{3}$-ammonia adducts. This could indicate that carbon released as more reactive ethane, rather than less reactive methane, is detrimental to the CVD process of GaN. As our attempts to achieve a continuous GaN film, both by varying N/Ga (through changing the partial pressure of the trimethylamine) and by varying the partial pressures of both trimethylamine and trimethylgallium while keeping a fixed $\mathrm{N} / \mathrm{Ga}$, all resulted in formation of droplets and cones. And, a higher partial pressure of the amine, which should be beneficial for adduct formation, always resulted in less growth of cones and formation of larger droplets. Furthermore, EDS mapping of the cones (Fig. S8) shows a significant carbon signal, likely originating from carbon adsorbed on the surface, as the solubility of carbon is very low in both $\mathrm{Ga}^{32}$ and $\mathrm{GaN}^{33}$. This can be interpreted as the trimethylamine or its gas phase reaction products, such as ethane, hindering the growth of $\mathrm{GaN}$, leaving droplets of metallic gallium on the surface. This reasoning can be extended to explain why no GaN films were grown using any of the methylamines: the amines or their reaction products could be passivating $\mathrm{GaN}$ surfaces, forcing the enhanced formation of metallic gallium droplets.

The presence of metallic droplets appears to favor a VLS-type growth mechanism of cones rather than films. The morphology from SEM, Figs. 5b and EDS mapping Fig. S8, suggests that the metallic gallium droplet is growing while also seeding growth of the cone, causing the growing cone to continually increase in diameter while it grows in length (Fig. 7) This shows similar behavior to the growth of $\mathrm{Ga}_{2} \mathrm{O}_{3}$ cones using an amidinate precursor and water. ${ }^{34}$ The material comprising the cone is not fully understood; as no peaks related to gallium oxide could be seen in the GIXRD pattern (Fig. S9) and considering the very weak tendency for gallium to form carbides ${ }^{35}$ and that nitrogen was detected in the cones by EDS (Fig. S8), a probable material in the cones is an X-ray amorphous gallium nitride. The high amount of carbon detected on the cones in EDS (Fig. S8) could disturb the nitride forming process, leading to an $\mathrm{X}$-ray amorphous gallium nitride structure. 


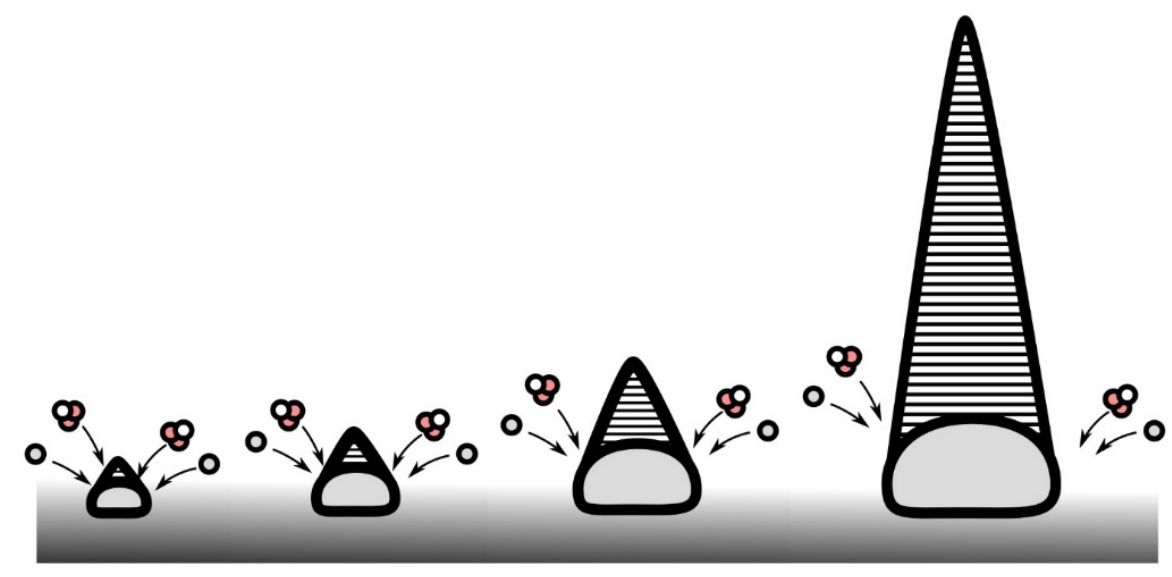

Figure 7: Schematics of a possible growth mechanism for the observed cones.

Although it was observed that low amine flow led to the formation of droplets and cones, and high amine flow led to no deposited species at all, it is unclear what the cause of this is. The formation of gallium metal droplets at the surface occurs more readily at low amine/Ga precursor ratio, $\mathrm{N} / \mathrm{Ga}=275$. Perhaps a gallium species, most likely $\mathrm{GaCH}_{3}$ with minor contribution from atomic $\mathrm{Ga},{ }^{31}$ reaches the surface and deposits gallium metal by reductive elimination of ethane:

$2 \mathrm{GaCH}_{3} \rightarrow 2 \mathrm{Ga}^{0}+\mathrm{C}_{2} \mathrm{H}_{6}$

This would be an irreversible process as there are no oxidizing agents present in the CVD gas mixture. Under low and intermediate amine flow, GaN could then nucleate on the growing droplet surface. Under high amine flow, where there was no apparent $\mathrm{GaN}$ formation, the gallium metal could be etched by the overpressure of amine by a subsequent oxidative addition:

$2 \mathrm{n} \mathrm{Ga}^{0}+3 \mathrm{n} \mathrm{N}\left(\mathrm{CH}_{3}\right)_{3} \rightarrow \mathrm{n}-\mathrm{x}\left(\mathrm{CH}_{3}\right)_{2} \mathrm{Ga}^{\mathrm{III}} \mathrm{N}\left(\mathrm{CH}_{3}\right)_{2}+\mathrm{x} \mathrm{CH}_{3} \mathrm{Ga}^{\mathrm{III}}\left(\mathrm{N}\left(\mathrm{CH}_{3}\right)_{2}\right)_{2}$

Another explanation for the enhanced formation of Ga droplets is a reversible blocking of surface sites by the methylamines reaction products, partially preventing growth of GaN, forcing incoming gallium species to adsorb in a such a way that reductive elimination of alkanes is favored.

\section{Concluding remarks}

From quantum chemical computations we find that methylamines show a higher reactivity in the gas phase chemistry of a CVD process for group 13 nitrides than (the currently used precursor) ammonia, while ammonia and its decomposition products show a higher reactivity 
towards a GaN surface than methylamines and their decomposition products. CVD experiments where ammonia was replaced by $\mathrm{NH}_{3-\mathrm{x}}\left(\mathrm{CH}_{3}\right)_{\mathrm{x}}$ with $\mathrm{x}=1,2$ or 3 , did not deposit continuous films, and instead the experiments rendered micrometer sized gallium droplets. At some experimental conditions, cone shaped outgrowths from the droplets, probably consisting of Xray amorphous GaN, were observed. This study shows that in the search to replace ammonia with a more efficient nitrogen precursor in CVD of the group 13 nitrides, allowing for a N/13 ratio closer to unity and lower CVD temperatures, the surface chemistry of the reaction fragments is likely more important than a more reactive gas phase chemistry. The results also suggest that care should be taken to avoid formation of too-reactive hydrocarbon fragments of any new nitrogen precursor.

\section{Acknowledgements}

This project was founded by the Swedish foundation for Strategic Research through the project “Time-resolved low temperature CVD for III-nitrides" (SSF-RMA 15-0018). STB and SCB acknowledge the Vinnova VINNMER Marie Curie incoming mobility program for funding for a sabbatical and research visits to Linköping University (Vinnova grant 2015-03714). HP and STB are very grateful for the networking support provided from the COST Action MP1402 'Hooking together European research in atomic layer deposition (HERALD) supported by COST (European Cooperation in Science and Technology). LO acknowledges financial support from the Swedish Government Strategic Research Area in Materials Science on Functional Materials at Linköping University (Faculty Grant SFO Mat LiU No. 2009 00971). Supercomputing resources were provided by the Swedish National Infrastructure for Computing (SNIC) and the Swedish National Supercomputer Centre (NSC). Urban Forsberg and Chih-Wei Hsu are gratefully acknowledged for technical assistance with the CVD reactor.

\section{Supporting information}

Graphs corresponding to tables 1-6; Ball-and-stick pictures of the optimized molecular geometries; Adduct formation geometries and energies with $\mathrm{Al}\left(\mathrm{CH}_{3}\right)_{3}$ and $\mathrm{NH}_{3-\mathrm{x}}\left(\mathrm{CH}_{3}\right)_{\mathrm{x}}$; EDS and GIXRD measurements of droplets and cones. 


\section{References}

(1) Davis, R. F. Organometallic Vapor Phase Epitaxial Growth of Group III Nitrides. Compr. Semicond. Sci. Technol. 2011, 3, 339-367.

(2) Mihopoulos T. G.; Gupta V.; Jensen K. F. A reaction-transport model for AlGaN MOVPE growth. J. Cryst. Growth 1998, 195, 733-739.

(3) Ravasio S.; Momose T.; Fujii K.; Shimogaki Y.; Sugiyama M.; Cavallotti C. Analysis of the gas phase kinetics active during $\mathrm{GaN}$ deposition from $\mathrm{NH}_{3}$ and $\mathrm{Ga}\left(\mathrm{CH}_{3}\right)_{3}$. J. Phys. Chem. A 2015, 119, 7858-7871.

(4) Bergmann U.; Reimer V.; Atakan B. An experimental study of the reactions of trimethylgallium with ammonia and water over a wide temperature range. Phys. Chem. Chem. Phys. 1999, 1, 5593-5599.

(5) Sekiguchi K.; Shirakawa H.; Chokawa K.; Araidai M.; Kangawa Y.; Kakimoto K.; Shiraishi K. Thermodynamic analysis of trimethylgallium decomposition during GaN metal organic vapor phase epitaxy Jpn. J. Appl. Phys. 2018, 57, 04FJ03.

(6) Creighton J. R.; Wang G. T. Kinetics of Metal Organic-Ammonia Adduct Decomposition: Implications for Group-III Nitride MOCVD. J. Phys. Chem. A 2005, 109, $10554-10562$.

(7) An Q.; Jaramillo-Botero A.;Liu W.-G.; Goddard W. A. Reaction Pathways of GaN (0001) Growth from Trimethylgallium and Ammonia versus Triethylgallium and Hydrazine Using First Principle Calculations J. Phys. Chem. C 2015 119, 4095-4103.

(8) Kakanakova-Georgieva, A.; Gueorguiev, G. K.; Stafström, S.; Hultman, L.; Janzén, E. AlGaInN metal-organic-chemical-vapor-deposition gas-phase chemistry in hydrogen and nitrogen diluents: First-principles calculations. Chem. Phys. Lett. 2006, 431, 346-351. 
(9) Nakamura, K.; Makino, O.; Tachibana, A.; Matsumoto, K. Quantum chemical study of parasitic reaction in III-V nitride semiconductor crystal growth. J. Organomet. Chem. 2000, $611,514-524$.

(10) Sengupta, D.; Mazumder, S.; Kuykendall, W.; Lowry, S. A. Combined ab initio quantum chemistry and computational fluid dynamics calculations for prediction of gallium nitride growth. J. Cryst. Growth 2005, 279, 369-382.

(11) Chen C. H.; Liu H.; Steigerwald D.; Imler W.; Kuo C. P.; Craford M. G.; Ludowise M.; Lester S.; Amano J. A study of parasitic reactions between NH3 and TMGa or TMAI J. Electron. Mater. 1996, 25, 1004-1008.

(12) Moscatelli D.; Caccioppoli P.; Cavallotti C. Ab initio study of the gas phase nucleation mechanism of GaN Appl. Phys. Lett. 2005, 86, 091106

(13) Hirako A.; Kusakabe K.; Ohkawa K. Modeling of Reaction Pathways of GaN Growth by Metalorganic Vapor-Phase Epitaxy Using TMGa/ $\mathrm{NH}_{3} / \mathrm{H}_{2}$ System: A Computational Fluid Dynamics Simulation Study Jpn. J. Appl. Phys. 2005, 44, 874-879.

(14) Ruffenach, S.; Moret, M.; Briot, O.; Gil, B. Recent advances in the MOVPE growth of indium nitride. Phys. Stat. Sol. A 2010, 207, 9-18.

(15) Beaumont B.; Gibart P.; Faurie J. P. Nitrogen precursors in metalorganic vapor phase epitaxy of (Al,Ga)N J. Cryst. Growth 1995, 156, 140-146.

(16) Konnov A. A.; De Ruyck J. Kinetic Modeling of the Thermal Decomposition of Ammonia. Combust. Sci. Technol. 2000, 152, 23-37.

(17) Liu, S. S.; Stevenson, D. A. Growth Kinetics and Catalytic Effects in the Vapor Phase Epitaxy of Gallium Nitride. J. Electrochem. Soc. 1978, 125, 1161-1169.

(18) Refers to the N-H bond dissociation energy in the $\mathrm{NH}_{3}$ molecule. Reference: "Bond dissociation energies in polyatomic molecules," in CRC Handbook of Chemistry and Physics, 
98th Edition (Internet Version 2018), John R. Rumble, ed., CRC Press/Taylor \& Francis, Boca Raton, FL.

(19) Refers to the N-C bond dissociation energy in the $\mathrm{NH}_{2} \mathrm{CH}_{3}$ molecule. Reference: "Bond dissociation energies in polyatomic molecules," in CRC Handbook of Chemistry and Physics, 98th Edition (Internet Version 2018), John R. Rumble, ed., CRC Press/Taylor \& Francis, Boca Raton, FL.

(20) Frisch, M. J. et al.; Trucks, G. W.; Schlegel, H. B.; Scuseria, G. E.; Robb, M. A.;

Cheeseman, J. R.; Scalmani, G.; Barone, V.; Mennucci, B.; Petersson, G. A.; et al. Gaussian 09; Gaussian, Inc.: Wallingford, CT, 2013.

(21) Curtiss, L. A.; Redfern, P. C.; Raghavachari, K. Gaussian-4 theory. J. Chem. Phys. 2007, 126, 084108.

(22) Curtiss, L. A.; Redfern, P. C.; Raghavachari, K. Assessment of Gaussian-4 theory for energy barriers Chem. Phys. Lett. 2010, 499, 1-3.

(23) Purvis G. D.; Bartlett R. J. A full coupled-cluster singles and doubles model: The inclusion of disconnected triples J. Chem. Phys. 1982, 76, 910-1918.

(24) Przhevalskii I. N.; Karpov S. Y.; Markarov Y. N. Thermodynamic properties of group-III nitrides and related species MRS Internet J. Nitride Semicond. Res. 1998, 3, 30

(25) Creighton J. R.; Wang G. T. Reversible adduct formation of trimethylgallium and trimethylindium with ammonia J. Phys. Chem. A 2005, 109, 133-137.

(26) Grimme, S.; Antony, J.; Ehrlich, S.; Krieg, H. A consistent and accurate ab initio parameterization of density functional dispersion correction (DFT-D) for the 94 elements HPu. J. Chem. Phys. 2010, 132, 154104.

(27) McQuarrie, D. A.; Simon, J. D. Molecular Thermodynamics. University Science Books: Sausalito, CA, 1999. 
(28) Forsberg, U.; Lundskog, A.; Kakanakova-Georgieva, A.; Ciechonski, R.; Janzén, E. Improved hot-wall MOCVD growth of highly uniform $\mathrm{AlGaN} / \mathrm{GaN} / \mathrm{HEMT}$ structures. $J$. Cryst. Growth 2009, 311, 3007-3010.

(29) Kern, W.; Puotinen, D. A. Cleaning Solutions Based on Hydrogen Peroxide for use in Silicon Semiconductor Technology. RCA Review, 1970, June, 187-206.

(30) Kakanakova-Georgieva, A.; Forsberg, U.; Ivanov, I. G.; Janzén, E. Uniform hot-wall MOCVD epitaxial growth of 2 inch AlGaN/GaN HEMT structures. J. Cryst. Growth 2007, $300,100-103$.

(31) Danielsson, Ö.; Li, X.; Ojamäe, L.; Janzén, E.; Pedersen, H.; Forsberg, U. A model for carbon incorporation from trimethyl gallium in chemical vapor deposition of gallium nitride. J. Mater. Chem. C 2016, 4, 863-871.

(32) Fujita, J.; Ueki, R.; Miyazawa, Y.; Ichihashi, T. Graphitization at interface between amorphous carbon and liquid gallium for fabricating large area graphene sheets. J. Vac. Sci. Technol. B 2009, 27, 3063-3066.

(33) Boguslawski, P.; Briggs, E. L.; Bernholc, J. Amphoteric properties of substitutional carbon impurity in GaN and AlN. Appl. Phys. Lett. 1996, 69, 233-235.

(34) Pallister, P. J.; Buttera, S. C.; Barry, S. T. Self-seeding gallium oxide nanowire growth by pulsed chemical vapor deposition. Phys. Stat. Sol. A 2015, 212, 1514-1518.

(35) Jansson, U.; Lewin, E. Sputter deposition of transition-metal carbide films - a critical review from a chemical perspective. Thin Solid Films 2013, 536, 1-24. 
TOC image:

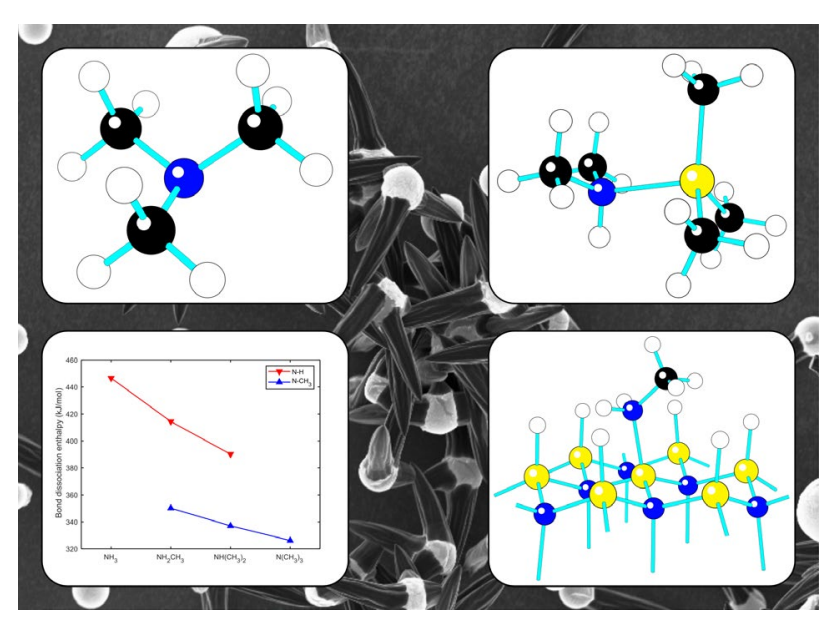


Supporting information to:

\section{Methylamines as Nitrogen Precursors in Chemical Vapor Deposition of Gallium Nitride}

Karl Rönnby ${ }^{1 *}$, Sydney C. Buttera ${ }^{2}$, Polla Rouf ${ }^{1}$, Seán T. Barry², Lars Ojamäe ${ }^{1}$, Henrik Pedersen $^{1}$

${ }^{1}$ Department of Physics, Chemistry and Biology, Linköping University, SE-581 83 Linköping, Sweden

${ }^{2}$ Department of Chemistry, Carleton University, 1125 Colonel By Drive, Ottawa, ON, Canada, K1S5B6

*Corresponding author: henrik.pedersen@liu.se; Twitter: @hacp81
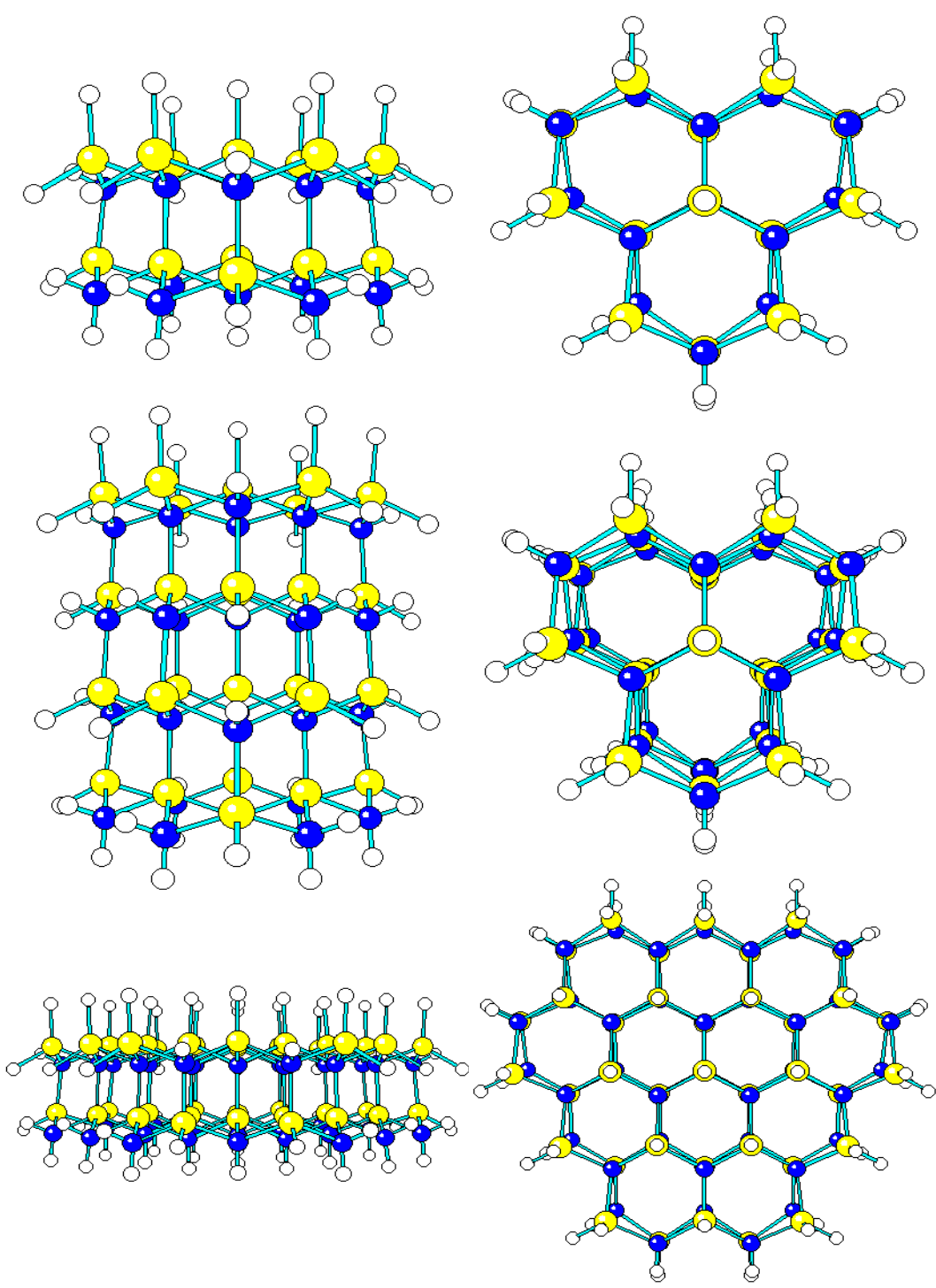

Figure S1: The three hydrogen terminated gallium nitride cluster used to evaluate the cluster size; top the smaller $(\mathrm{GaN})_{13} \mathrm{H}_{32}$, middle the two layer $(\mathrm{GaN})_{26} \mathrm{H}_{50}$ and bottom the larger $(\mathrm{GaN})_{37} \mathrm{H}_{68}$. Viewed along the symmetry axis on the right and from the side at the left. Yellow atoms are gallium, blue are nitrogen and white are hydrogen. 


\section{Evaluation of $\mathbf{G 4}$ method}

The bond energy for the gallium-carbon bond was calculated at both G4 and CCSD(T)/aug-cc-pVTZ ${ }^{1}$ level of theory as an evaluation of the $\mathrm{G} 4$ method. The bond energy was estimated by the electronic energy of the reaction $\mathrm{Ga}\left(\mathrm{CH}_{3}\right)_{3} \rightarrow \mathrm{Ga}\left(\mathrm{CH}_{3}\right)_{2}+\mathrm{CH}_{3}$. Geometries of the reactant and products were optimized at the B3LYP/6-31G(2df,p) level of theory. The reaction energy calculated with $\mathrm{G} 4$ was $317 \mathrm{~kJ} / \mathrm{mol}$ while the energy from CCSD(T) was $328 \mathrm{~kJ} / \mathrm{mol}$.

\section{Size of surface model cluster}

The size of the cluster was investigated by computation of the reaction energy of the adsorption of $\mathrm{NH}_{3}$ onto a hydrogen terminated cluster, releasing a hydrogen molecule. The reaction energy was computed at B3LYP $2,3 / 6-31 \mathrm{G}^{4}$ level of theory. Three different clusters were investigated; a smaller $(\mathrm{GaN})_{13} \mathrm{H}_{32}$, a two-layer $(\mathrm{GaN})_{26} \mathrm{H}_{50}$ and a larger $(\mathrm{GaN})_{37} \mathrm{H}_{68}$. The energy for adsorption was calculated to $-54.6 \mathrm{~kJ} / \mathrm{mol}$ for the smaller cluster, $-52.9 \mathrm{~kJ} / \mathrm{mol}$ for the two-layer cluster and $-54.8 \mathrm{~kJ} / \mathrm{mol}$ for the larger cluster. Since the difference in energy (less than $2 \mathrm{~kJ} / \mathrm{mol}$ ) was very small between the different clusters and that the smaller cluster allowed us to use a larger basis set we opted to use the smaller cluster in the computational study.

\section{Treatment of internal rotations}

The calculation of activation Gibbs free energies were normally performed treating all movements within the molecule as harmonic vibrational modes. The errors in energies associated with the approximation of treating internal rotations as vibration modes were investigated for reaction $\mathrm{BC} 2$ $\left(\mathrm{NH}\left(\mathrm{CH}_{3}\right)_{2}+\mathrm{H} \rightarrow \mathrm{NH}\left(\mathrm{CH}_{3}\right)_{2} \mathrm{H}^{\ddagger} \rightarrow \mathrm{NHCH}_{3}+\mathrm{CH}_{4}\right)$. Frequency calculations were performed at the B3LYP/6$31 \mathrm{G}(2 \mathrm{df}, \mathrm{p})$ level of theory where the frequencies were scaled by the factor 0.9854 in the same manner as in the G4 method. The enthalpies and free energies of the reaction and transition states when the internal rotations were treated as vibrations were compared to the energies obtained by correcting for the presence of rotations using the hindered-rotor approximation. ${ }^{5}$ As seen in Fig. S2 the largest differences were found for the free energy at high temperatures, but the differences in both enthalpies and free energies were even so less than $3.5 \mathrm{~kJ} / \mathrm{mol}$.

\footnotetext{
${ }^{1}$ Kendall R. A.; Dunning T. H. Jr.; Harrison R. J. Electron affinities of the first-row atoms revisited. Systematic basis sets and wave functions. J. Chem. Phys., 1992, 96, 6796-806

${ }^{2}$ Becke A.D. Density-functional exchange-energy approximation with correct asymptotic behavior. Phys. Rev. A, 1988, 38, 3098

${ }^{3}$ Lee C.; Yang W.; Parr R. G.; Development of the Colle-Salvetti correlation-energy formula into a functional of the electron density. Phys. Rev. B, 1988, 37, 785

${ }^{4}$ Hehre W. J.; Dichfield R.; People J. A. Self-Consistent Molecular Orbital Methods. XII. Further Extensions of Gaussian-Type Basis Sets for Use in Molecular Orbital Studies of Organic Molecules. J. Chem. Phys. 1972, 56, 2257

${ }^{5}$ McClurg R. B.; Flagan R. C.; Goddard W. A. III The hindered rotor density-of-states interpolation function. J. Chem. Phys., 1997, 106, 6675
} 
$\Delta \mathrm{H}^{\ddagger}$

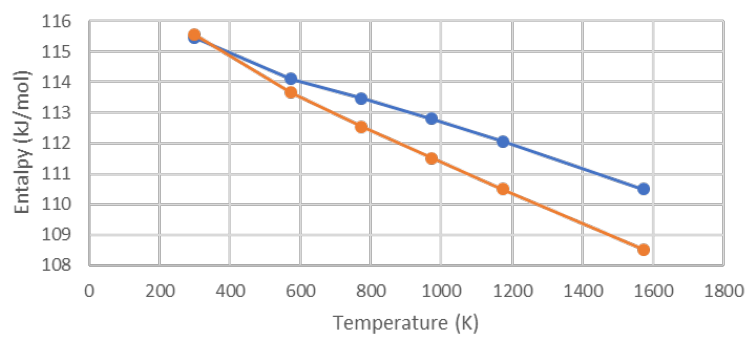

$\rightarrow$ All as vibrations $\rightarrow$ Internal rotations

$\Delta \mathrm{G}^{\ddagger}$

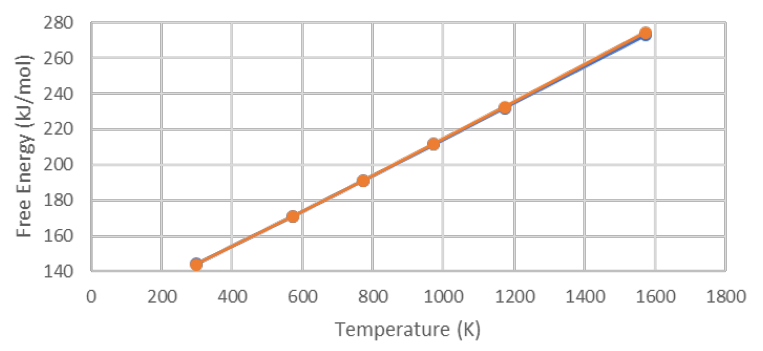

$\multimap$ All as vibrations $\quad \longrightarrow$ Internal rotations
$\Delta_{\mathrm{r}} \mathrm{H}$

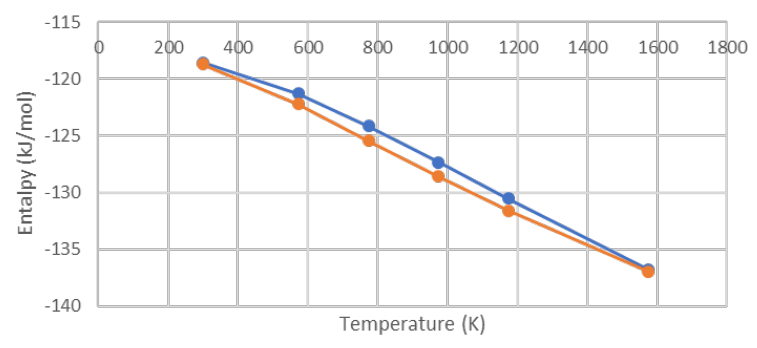

$\multimap$ All as vibrations $\rightarrow$ Internal rotations

$\Delta \mathrm{r}$

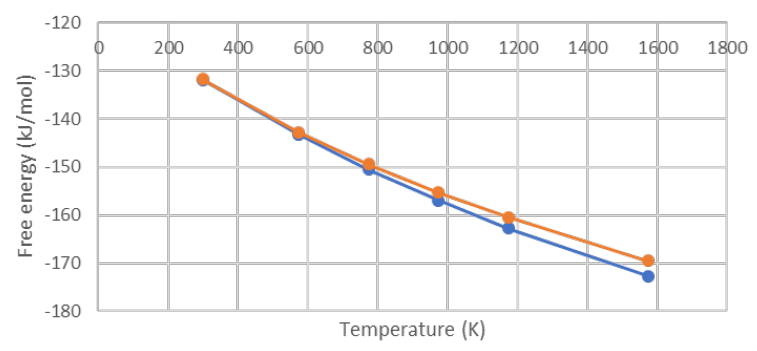

$\multimap$ All as vibrations $\quad \longrightarrow$ Internal rotations

Figure S2: Activation enthalpy and free energy of the transition state and the reaction enthalpy and free energy for reaction BC2. Blue without correction for internal rotations and orange with corrections. 
$\Delta_{\mathrm{r}} \mathrm{H}$

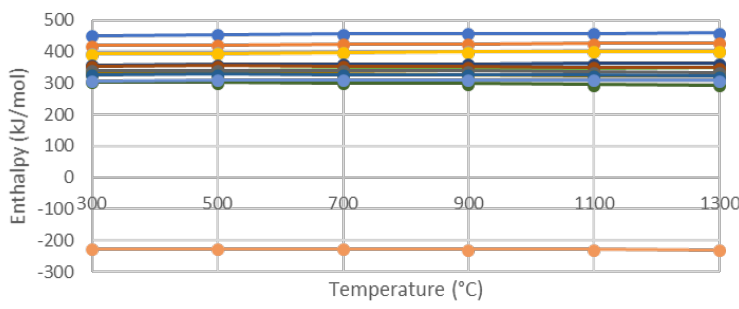

$\longrightarrow \mathrm{AH} 1 \longrightarrow \mathrm{AH} 2 \longrightarrow \mathrm{AH} 3 \longrightarrow \mathrm{AH} 4 \longrightarrow \mathrm{AH} 5 \longrightarrow \mathrm{AH} 6 \longrightarrow \mathrm{AH} 5$

$\multimap \mathrm{AC} 1 \rightarrow \mathrm{AC2} \longrightarrow \mathrm{AC} 3 \longrightarrow \mathrm{AC} 4 \longrightarrow \mathrm{AC} 5 \multimap \mathrm{AC} 6 \multimap \mathrm{RE}$

$\Delta_{\mathrm{r}} \mathrm{H}$

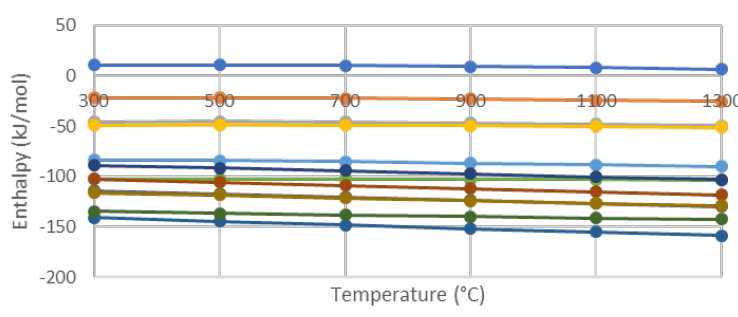

$\longrightarrow \mathrm{BH} 1 \longrightarrow \mathrm{BH}_{2} \longrightarrow \mathrm{BH}_{3}-\bullet-\mathrm{BH} 4 \longrightarrow \mathrm{BH} 5-\mathrm{BH} 6$

$\longrightarrow \mathrm{BC} 1 \longrightarrow \mathrm{BC2} \longrightarrow \mathrm{BC} 3 \longrightarrow \mathrm{BC} 4 \longrightarrow \mathrm{BC} 5 \longrightarrow \mathrm{BC}$

$\Delta_{\mathrm{r}} \mathrm{H}$

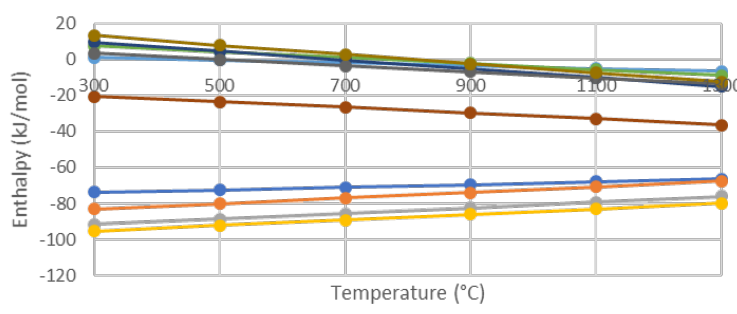

$\rightarrow$ CA1 $\rightarrow$ CA2 $\bullet-\mathrm{CA} 3-\mathrm{CA} 4 \rightarrow \mathrm{CM} 1$

$\bullet-\mathrm{CM} 2 \rightarrow \mathrm{CM} 3 \rightarrow \mathrm{CE} 1 \rightarrow \mathrm{CE} 2 \rightarrow \mathrm{CE} 3$

$\Delta_{\mathrm{r}} \mathrm{H}$

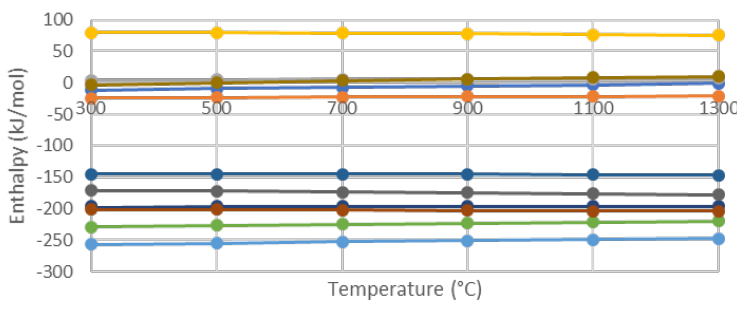

$\multimap$ D30 $\multimap-D 31 \multimap D$ D32 $-\bullet-D 33 \multimap D 20-D 21$

$\longrightarrow \mathrm{D} 22 \longrightarrow \mathrm{D} 10 \longrightarrow \mathrm{D} 11 \longrightarrow \mathrm{DRE} \rightarrow \mathrm{D} 00$
$\Delta \mathrm{r}$

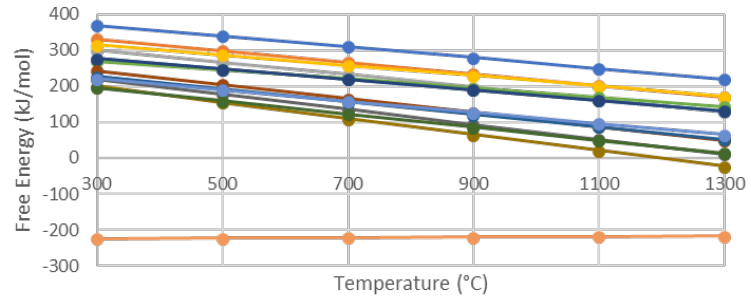

$\longrightarrow \mathrm{AH} 1 \longrightarrow \mathrm{AH}_{2} \longrightarrow \mathrm{AH} 3 \longrightarrow \mathrm{AH} 4 \longrightarrow \mathrm{AH} 5 \longrightarrow \mathrm{AH} 6 \rightarrow \mathrm{AH} 5$

$\longrightarrow \mathrm{AC} 1 \longrightarrow \mathrm{AC2} \longrightarrow \mathrm{AC} \longrightarrow \rightarrow \mathrm{AC} 4 \longrightarrow \mathrm{AC} 5 \longrightarrow \mathrm{AC} 6 \longrightarrow \mathrm{RE}$

$\Delta \mathrm{r}$

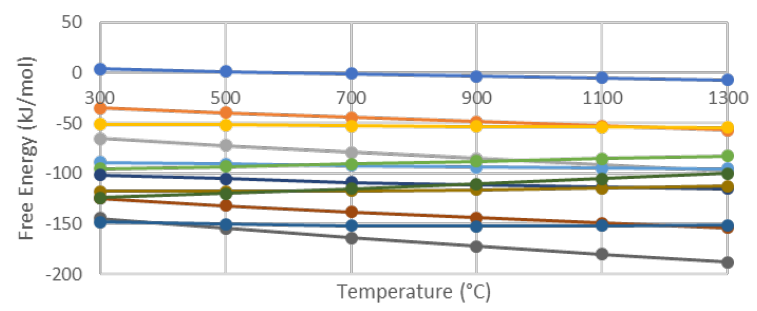

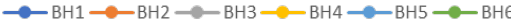

$\bullet \mathrm{BC} 1 \multimap \mathrm{BC2} \longrightarrow \mathrm{BC} 3 \multimap \mathrm{BC} 4 \longrightarrow \mathrm{BC} 5 \multimap \mathrm{BC} 6$

$\Delta_{\mathrm{r}} \mathrm{G}$

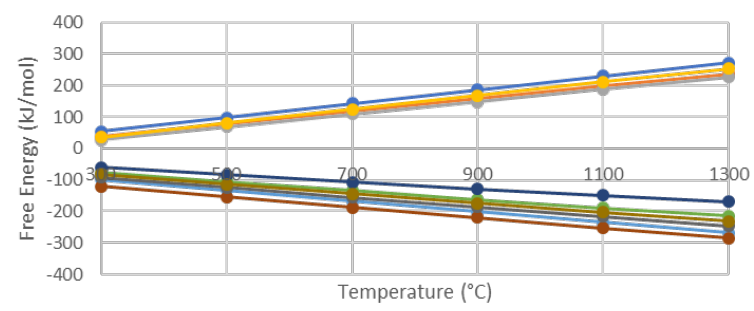

$\rightarrow$ CA1 $\bullet-\mathrm{CA} 2 \multimap \mathrm{CA} 3-\bullet-\mathrm{CA} 4 \rightarrow \mathrm{CM} 1$

$\bullet \mathrm{CM} 2 \rightarrow \mathrm{CM} 3 \multimap \mathrm{CE} 1 \rightarrow \mathrm{CE} 2 \multimap \mathrm{CE3}$

$\Delta_{\mathrm{r}} \mathrm{G}$

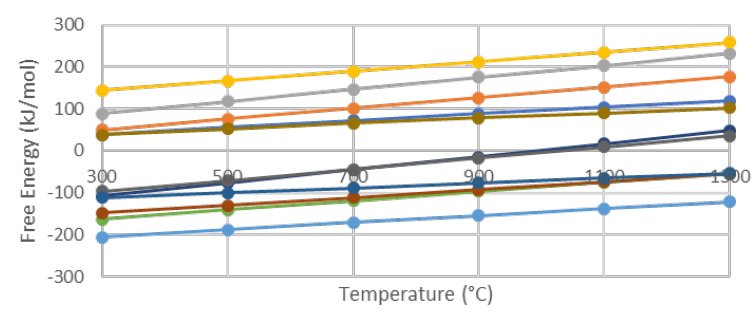

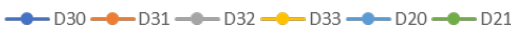

$\bullet \mathrm{D} 22 \rightarrow \mathrm{D} 10 \multimap \mathrm{D} 11 \rightarrow \mathrm{DRE} \rightarrow \mathrm{D} 00$

Figure S3: Reaction enthalpy and free energy for all gas phase and adsorption reactions, with the designations of the reactions from Scheme 1 and Scheme 2 in the article. 
$\Delta^{\ddagger} \mathrm{H}$

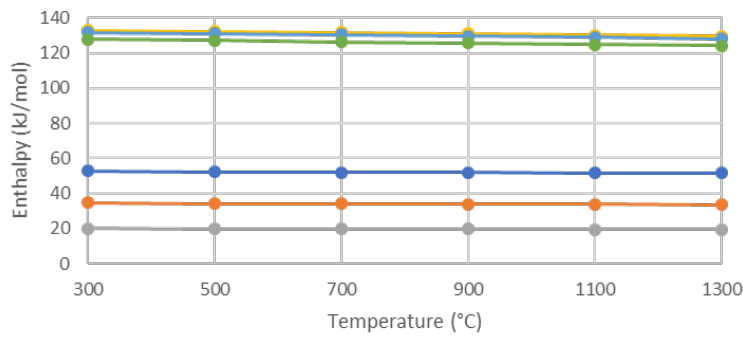

$\Delta^{\ddagger} \mathrm{H}$

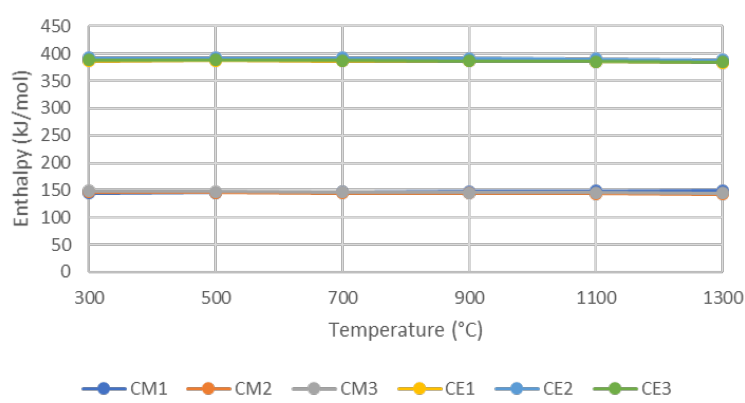

$\Delta^{\ddagger} G$

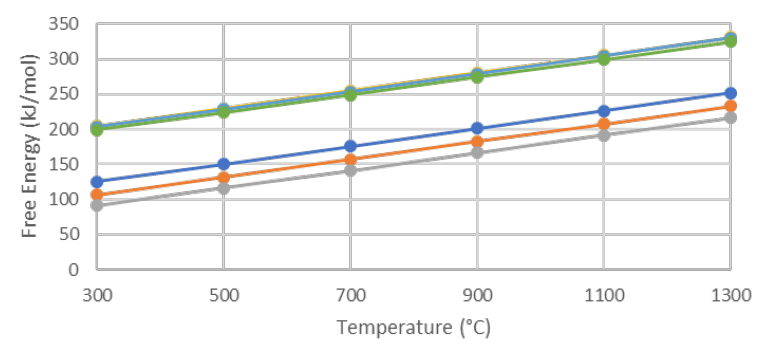

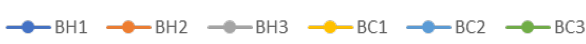

$\Delta^{\ddagger} G$

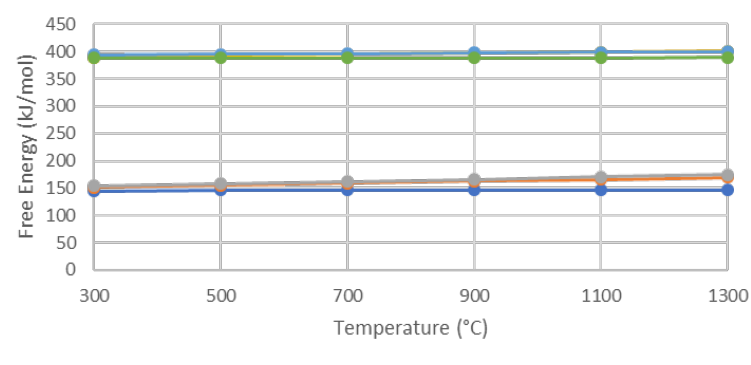

$\multimap \mathrm{CM} 1 \multimap \mathrm{CM} 2 \multimap \mathrm{CM} 3 \multimap \mathrm{CE} 1 \multimap \mathrm{CE} 2 \multimap \mathrm{CE} 3$

Figure S4: Transition state enthalpy and free energy for all gas phase and adsorption reactions, with the designations of the reactions from Scheme 1 and Scheme 2 in the article.
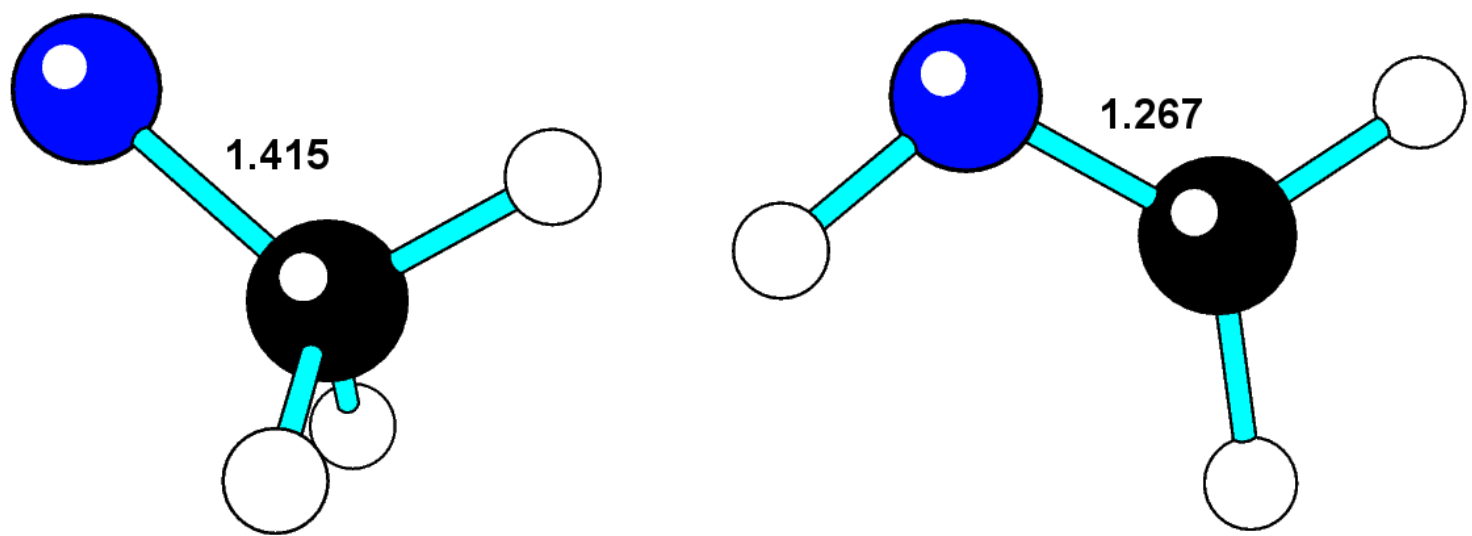

Figure S5: Reactant and product geometries for the rearrangement of $\mathrm{NCH}_{3}$ to $\mathrm{NHCH}_{2}$. Bond length of the carbon-nitrogen is bond given in $\AA$. Blue atoms are nitrogen, black are carbon and white are hydrogen. 

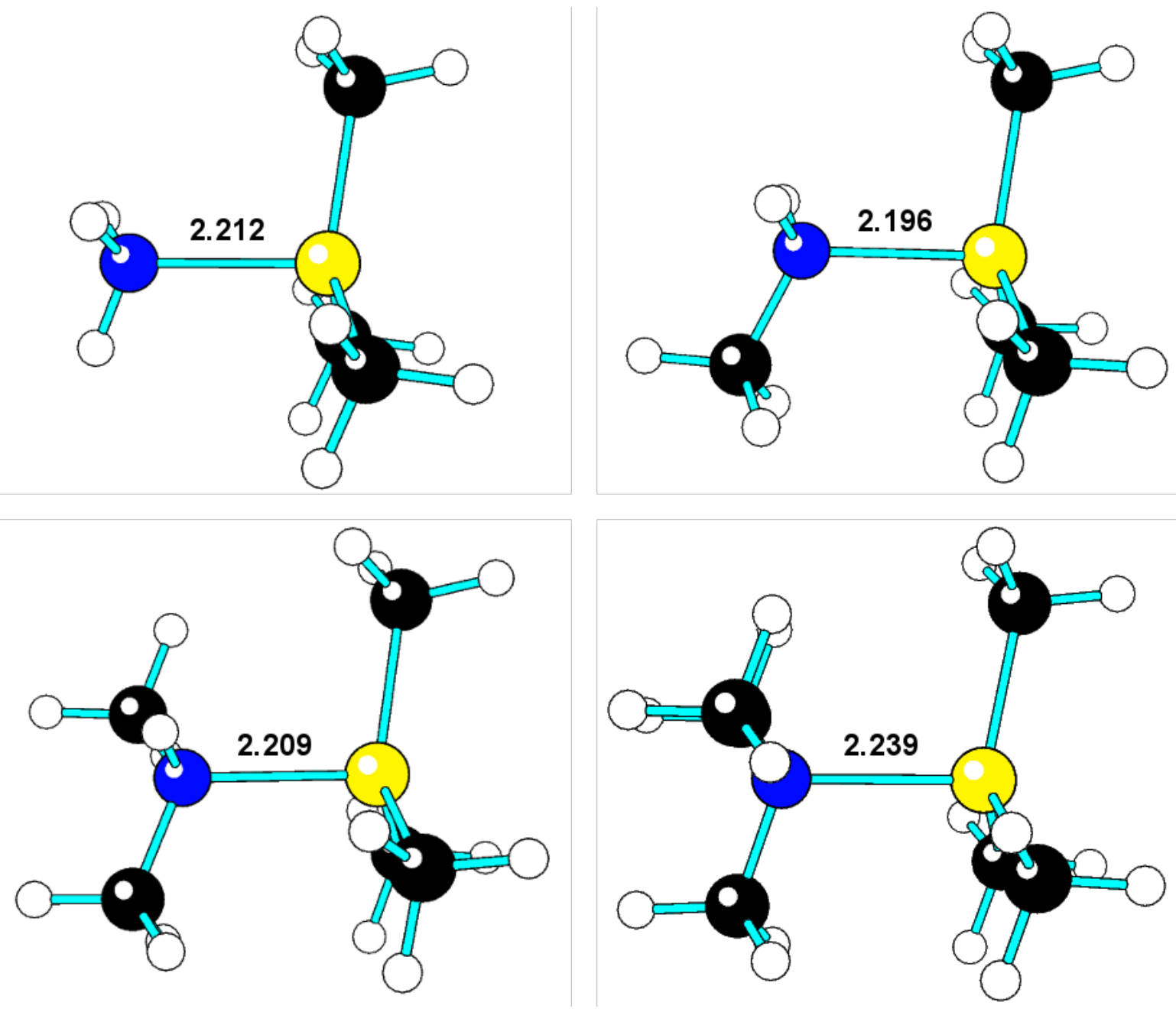

Figure S6: Geometry-optimized structures for the Lewis adducts formed between $\mathrm{NH}_{3-\mathrm{x}}\left(\mathrm{CH}_{3}\right)_{\mathrm{x}}$ and $\mathrm{Ga}\left(\mathrm{CH}_{3}\right)_{3}$. The Ga-N distance is given in $\AA$. Yellow atoms are gallium, blue are nitrogen, black are carbon and white are hydrogen.

\section{Adduct formation between $\mathrm{NH}_{3-x}\left(\mathrm{CH}_{3}\right)_{x}$ and $\mathrm{Al}\left(\mathrm{CH}_{3}\right)_{3}$ (TMA)}

Figure $\mathrm{S} 6$ shows the TMA adduct complexes after the geometry optimization with the Al-N bond lengths indicated. The reaction energies for the adduct reactions between ammonia or the methylamines and TMA are listed in Table S1 at CVD temperatures and pressure. As with the reaction with TMG, the adduct formation reactions with TMA are exothermic at all calculated temperatures, but the reaction enthalpies are less negative at higher temperatures. The reaction free energies at CVD conditions are all positive, but the forming of the adduct between dimethylamine and trimethylaluminum at $300^{\circ} \mathrm{C}$. As in the TMG case, the effect of the temperature increases the reaction free energy making the reactions less favorable at high temperatures. The adducts reaction with ammonia, methylamine and dimethylamine have similar reaction free energy and the difference is lower at higher temperatures. The reaction free energies of the adduct formation with trimethylamine is much higher than for the rest of the adduct reactions and a difference to that of the TMG case is that this reaction has the most positive reaction free energy for all CVD temperatures. The release of methane and ethane from the TMA adducts are more exothermic than the release from the TMG adducts. 
The reaction free energy is negative for all reaction due to them being entropic favorable. As with the TMG case the releases have higher entropy as the nitrogen gets more methyl groups and that the release of ethane is more favorable than the release of methane when both could be released.

The sum reactions for the adduct formation and release of methane and ethane are exothermic at all temperatures. All reactions but the formation of the adduct of TMA and dimethylamine and release of methane, which have a positive reaction free energy at higher temperatures, have negative reaction free energy at all temperatures.
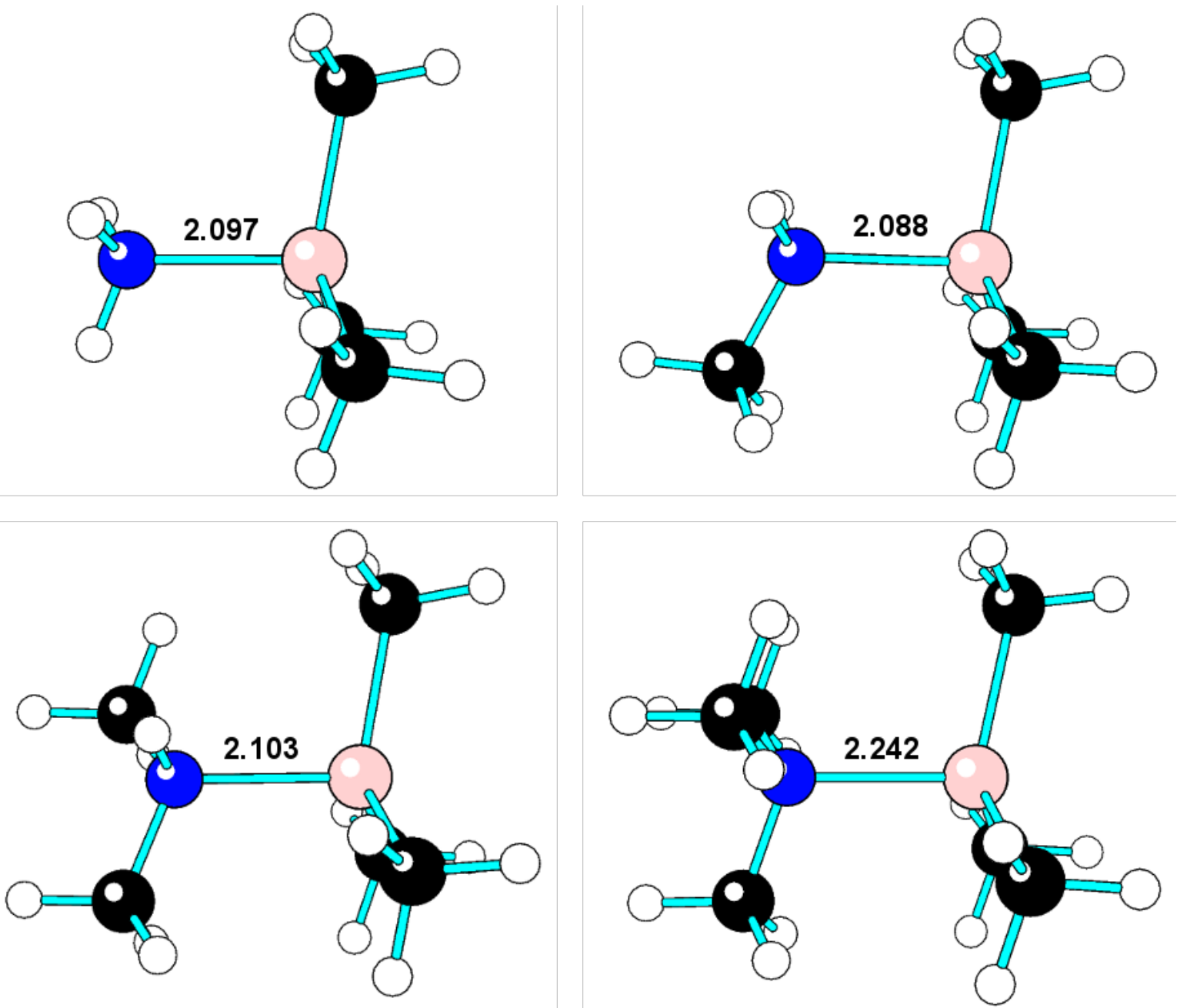

Figure S7: Geometry optimized structures for the Lewis adducts formed between $\mathrm{NH}_{3-\mathrm{x}}\left(\mathrm{CH}_{3}\right)_{\mathrm{x}}$ and $\mathrm{Al}\left(\mathrm{CH}_{3}\right)_{3}$. The Al-N distance is given in $\AA$. Salmon-colored atoms are aluminum, blue are nitrogen, black are carbon and white are hydrogen. 
Table S1: Adduct formation of between $\mathrm{NH}_{3-x}\left(\mathrm{CH}_{3}\right)_{x}$ and $\mathrm{Al}\left(\mathrm{CH}_{3}\right)_{3}(\mathrm{TMA})$ and subsequent hydrocarbon elimination reactions at CVD conditions: $300^{\circ} \mathrm{C}-1300^{\circ} \mathrm{C}$ and $50 \mathrm{mbar}$. All energies are given in $\mathrm{kJ} / \mathrm{mol}$.

\begin{tabular}{|l|rrrrr|rrrrrrr|}
\hline & \multicolumn{7}{|c|}{$\Delta_{\mathrm{r}} \mathrm{H}^{\circ}$} & \multicolumn{6}{c|}{$\Delta_{\mathrm{r}} \mathrm{G}^{\circ}$} \\
\cline { 2 - 10 } & $300^{\circ} \mathrm{C}$ & $500^{\circ} \mathrm{C}$ & $700^{\circ} \mathrm{C}$ & $900^{\circ} \mathrm{C}$ & $1100^{\circ} \mathrm{C} 1300^{\circ} \mathrm{C}$ & $300^{\circ} \mathrm{C}$ & $500^{\circ} \mathrm{C}$ & $700^{\circ} \mathrm{C}$ & $900^{\circ} \mathrm{C}$ & $1100^{\circ} \mathrm{C} 1300^{\circ} \mathrm{C}$ \\
\hline SAA1 & -99.4 & -96.6 & -93.7 & -90.5 & -87.3 & -84.1 & 11.3 & 49.5 & 87.0 & 123.8 & 160.1 & 195.9 \\
SAA2 & -113.5 & -110.7 & -107.7 & -104.6 & -101.4 & -98.2 & 3.5 & 43.9 & 83.6 & 122.6 & 161.1 & 199.1 \\
SAA3 & -121.1 & -118.2 & -115.1 & -112.0 & -108.9 & -105.7 & -2.2 & 38.8 & 79.0 & 118.7 & 157.7 & 196.3 \\
SAA4 & -128.0 & -126.6 & -125.2 & -123.8 & -122.3 & -120.9 & 21.2 & 73.1 & 124.5 & 175.7 & 226.7 & 277.4 \\
& & & & & & & & & & & & \\
SAM1 & -10.6 & -13.6 & -16.7 & -20.0 & -23.3 & -26.6 & -93.7 & -122.3 & -150.0 & -177.1 & -203.6 & -229.6 \\
SAM2 & 3.4 & 0.2 & -3.1 & -6.4 & -9.7 & -13.0 & -84.9 & -115.3 & -144.7 & -173.5 & -201.8 & -229.5 \\
SAM3 & 6.7 & 1.7 & -3.3 & -8.3 & -13.2 & -18.2 & -65.8 & -90.3 & -113.5 & -135.7 & -157.0 & -177.6 \\
SAE1 & -27.5 & -30.4 & -33.5 & -36.7 & -40.0 & -43.4 & -124.7 & -158.2 & -190.9 & -222.9 & -254.4 & -285.4 \\
SAE2 & -1.9 & -5.3 & -8.7 & -12.2 & -15.6 & -19.0 & -102.6 & -137.2 & -170.9 & -203.9 & -236.4 & -268.3 \\
SAE3 & 13.4 & 9.7 & 6.1 & 2.6 & -0.8 & -4.2 & -102.2 & -142.0 & -180.8 & -218.8 & -256.3 & -293.3 \\
\hline
\end{tabular}

\section{Dispersion correction effects on surface interaction energies}

In Table S2 are listed the surface interaction reaction energies using the functional B3LYP but now instead without empirical dispersion for comparison with the values including the correction in Table 6. For most reactions the difference between the two calculations with and without the dispersion is less than $50 \mathrm{~kJ} / \mathrm{mol}$ and the difference increases as the temperature is increased. The larges difference in energy was for the adsorption of rearranged methanimine. 
Table S2: Surface interaction of ammonia and methylamines with GaN at CVD conditions, i.e. $300^{\circ} \mathrm{C}-1300^{\circ} \mathrm{C}$ at $50 \mathrm{mbar}$, modelled using the functional B3LYP but now without empirical dispersion included. All values are given in $\mathrm{kJ} / \mathrm{mol}$.

\begin{tabular}{|c|c|c|c|c|c|c|c|c|c|c|c|c|}
\hline & \multicolumn{6}{|c|}{$\Delta_{\mathrm{r}} \mathrm{H}^{\circ}$} & \multicolumn{6}{|c|}{$\Delta_{\mathrm{r}} \mathrm{G}^{\circ}$} \\
\hline & $300^{\circ} \mathrm{C}$ & $500^{\circ} \mathrm{C}$ & $700^{\circ} \mathrm{C}$ & $900^{\circ} \mathrm{C}$ & $1100^{\circ} \mathrm{C}$ & $1300^{\circ} \mathrm{C}$ & $300^{\circ} \mathrm{C}$ & $500^{\circ} \mathrm{C}$ & $700^{\circ} \mathrm{C}$ & $900^{\circ} \mathrm{C}$ & $1100^{\circ} \mathrm{C}$ & $1300^{\circ} \mathrm{C}$ \\
\hline D30 & 13.7 & 14.6 & 15.3 & 15.9 & 16.5 & 17.0 & 66.1 & 84.2 & 102.2 & 119.9 & 137.6 & 155.2 \\
\hline D31 & 16.1 & 17.1 & 17.8 & 18.4 & 18.9 & 19.4 & 86.5 & 110.9 & 135.1 & 159.2 & 183.2 & 207.0 \\
\hline D32 & 40.5 & 41.4 & 41.9 & 42.4 & 42.8 & 43.1 & 121.9 & 150.2 & 178.4 & 206.3 & 234.4 & 262.1 \\
\hline D33 & 111.9 & 111.7 & 111.0 & 110.0 & 108.8 & 107.5 & 175.2 & 197.3 & 219.5 & 241.9 & 264.5 & 287.2 \\
\hline D20 & -239.8 & -237.6 & -235.7 & -233.8 & -232.1 & -230.4 & -185.0 & -166.2 & -147.9 & -130.1 & -112.5 & -95.2 \\
\hline D21 & $\mid-197.8$ & -196.0 & -194.3 & -192.7 & -191.1 & -189.4 & -125.5 & -100.6 & -76.1 & -51.9 & -28.1 & -4.4 \\
\hline D22 & $\mid-151.0$ & -150.7 & -150.5 & -150.4 & -150.4 & -150.3 & -60.9 & -29.5 & 1.8 & 33.1 & 64.4 & 95.7 \\
\hline D10 & $\mid-188.1$ & -188.3 & -188.7 & -189.3 & -190.0 & -190.6 & -131.5 & -111.7 & -91.9 & -71.9 & -51.9 & -31.7 \\
\hline D11 & $\mid-144.2$ & -145.0 & -146.1 & -147.4 & -148.8 & -150.2 & -67.3 & -40.3 & -13.1 & 14.4 & 42.1 & 70.0 \\
\hline DRE & 25.6 & 29.2 & 32.1 & 34.6 & 36.9 & 39.0 & 80.8 & 99.5 & 117.3 & 134.6 & 151.4 & 168.0 \\
\hline D00 & $\mid-136.4$ & -136.2 & -136.3 & -136.7 & -137.2 & -137.7 & -97.1 & -83.4 & -69.7 & -56.0 & -42.2 & -28.3 \\
\hline
\end{tabular}



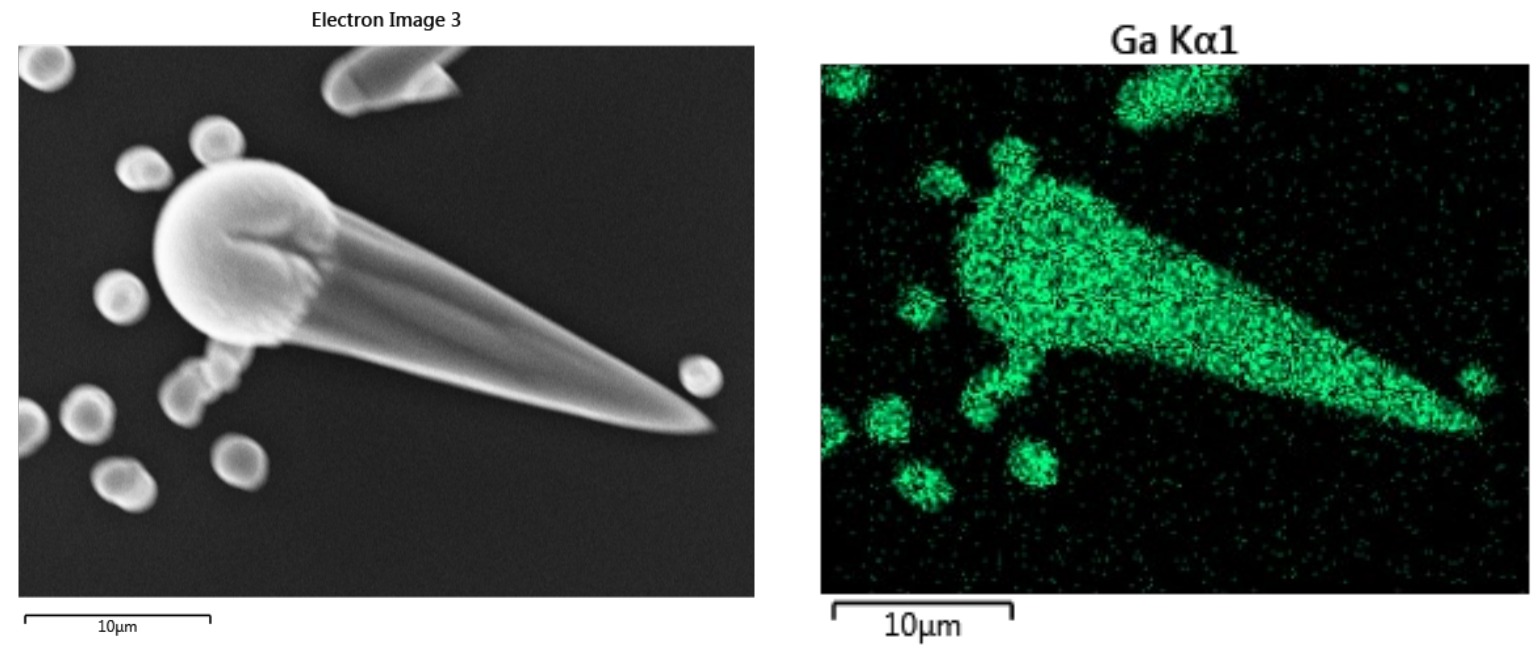

N K $\alpha 12$

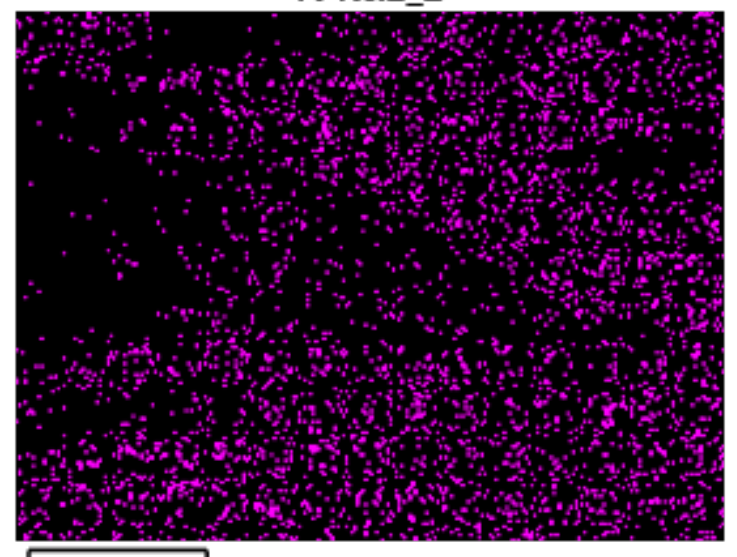

C Ko1_2

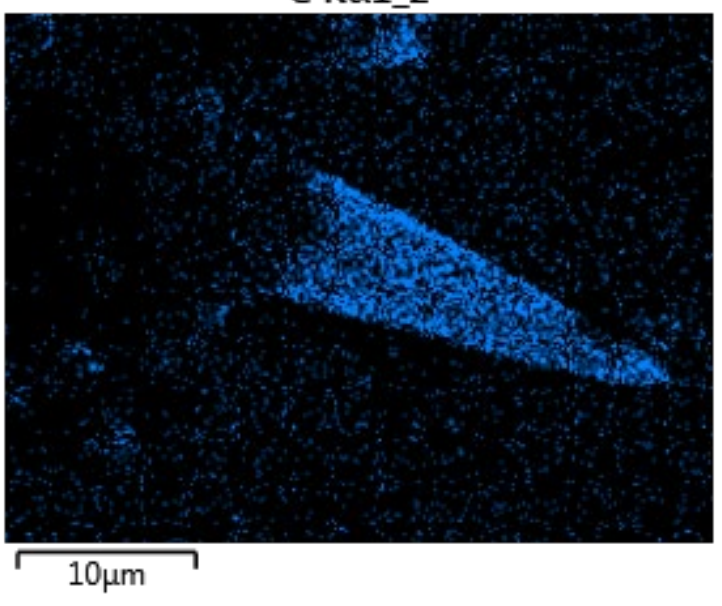

$\mathrm{O} K \alpha 1$
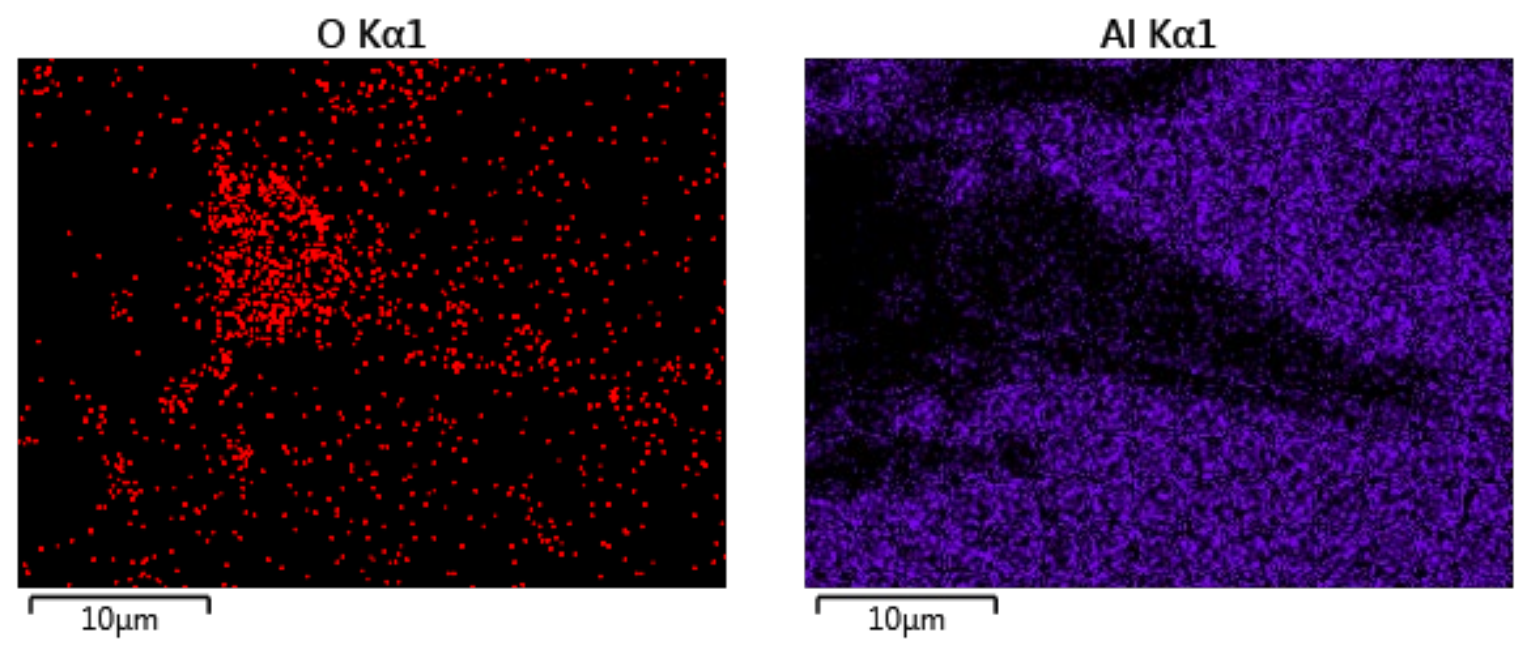

Figure S8: Elemental mapping by EDS of a droplet with a cone from a CVD samples grown at $925^{\circ} \mathrm{C}$ from $\mathrm{Ga}\left(\mathrm{CH}_{3}\right)_{3}$ and $\mathrm{N}\left(\mathrm{CH}_{3}\right)_{3}$ using $\mathrm{N} / \mathrm{Ga}=570$. 


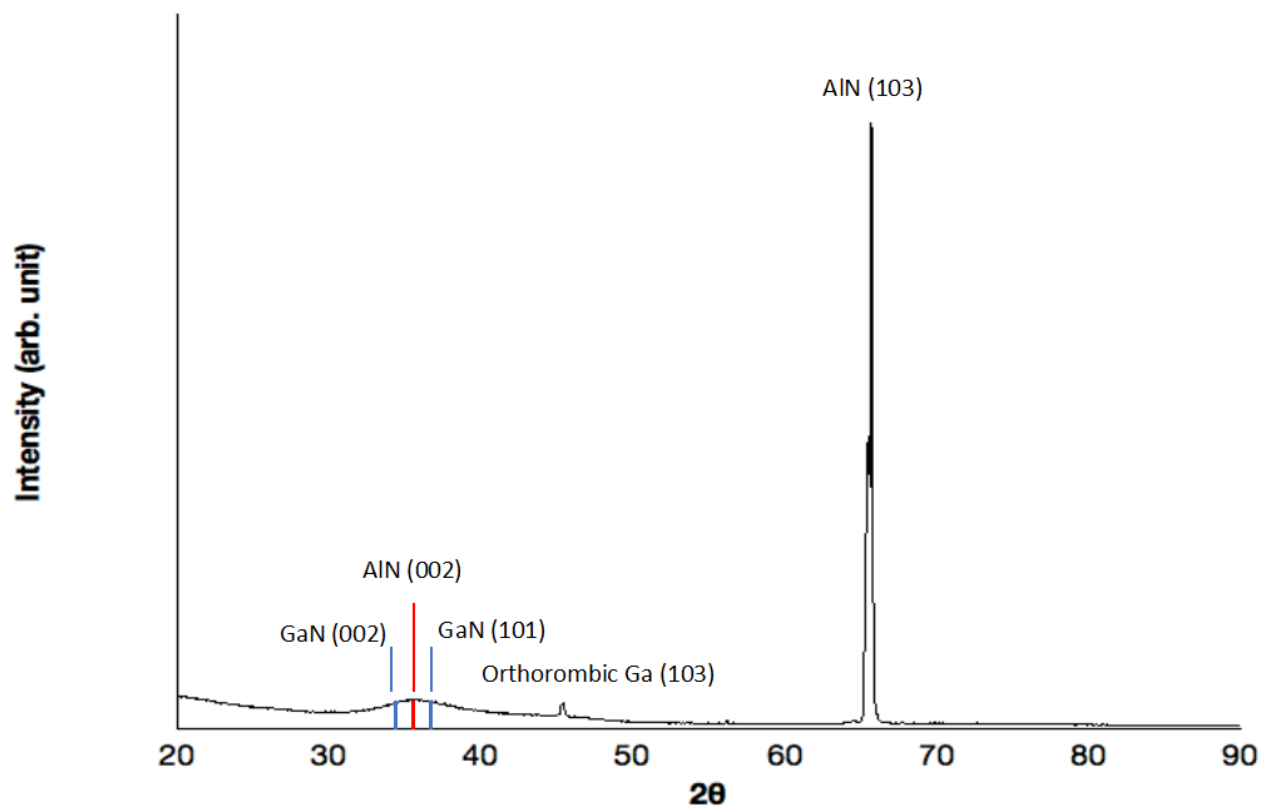

Figure S9: GIXRD of a CVD sample grown at $925^{\circ} \mathrm{C}$ from $\mathrm{Ga}\left(\mathrm{CH}_{3}\right)_{3}$ and $\mathrm{N}\left(\mathrm{CH}_{3}\right)_{3}$ using $\mathrm{N} / \mathrm{Ga}=570$ 